Article

\title{
The Hybrid Joints between an FRP Panel and a Steel Panel through Tubular Reinforcements: A Methodology for Interlaminar Stress Calculations
}

\author{
Franklin Domínguez ${ }^{1,2,3, *(\mathbb{D})}$ and Luis Carral ${ }^{4}$ (D) \\ 1 Doctoral Program, Universidade da Coruña, Campus Esteiro, 15403 Ferrol, Spain \\ Chimborazo 2912 y Garcia Goyena, Guayaquil 090114, Ecuador \\ 3 Escuela Superior Politécnica del Litoral, ESPOL, Facultad de Ingeniería Marítima y Ciencias del \\ Mar - FIMCM, ESPOL Polytechnic University, Campus Gustavo Galindo Km. 30.5 Vía Perimetral, \\ P.O. Box 09-01-5863, Guayaquil 090902, Ecuador \\ 4 Department of Naval and Industrial Engineering, Universidade da Coruña, Campus Esteiro, \\ 15403 Ferrol, Spain; lcarral@udc.es \\ * Correspondence: f.j.dominguez.ruiz@udc.es or jdominguez@tecnavin.com; Tel.: +59398-4166936
}

Received: 20 April 2020; Accepted: 2 June 2020; Published: 7 June 2020

\begin{abstract}
The advantages of laminates in terms of the chemical properties and mechanical properties/weight relationship have motivated several applications of fiber-reinforced plastic (FRP) composites in naval constructions due to the reduction in structural weight. This weight advantage has motivated multiple investigations dedicated to dissimilar material joints. We present a methodology for the interlaminar stress calculations of a tubular hybrid joint between an FRP panel and a steel panel through tubular reinforcements. The proposed formulas allow the estimation of the shear and normal stresses on the adhesive, which are generated in the bonding angle of the tubular hybrid joint. The stresses generated at the adhesive bonding ends influence on the adherent's adjacent layer. A failure criterion is shown to check the accomplishment of the resulting stresses in the adherent laminate. Finally, the proposed formulas are validated using the finite element method and compared with the obtained interlaminar stresses.
\end{abstract}

Keywords: hybrid joint; adhesive single-lap joint; interlaminar stress; tubular reinforcement joint; marine applications; composite

\section{Introduction}

The hybrid joint was developed from the technique of using adhesive and bolts to bond different materials, which are applied to join steel deck and fiber-reinforced plastic (FRP) panels. The different proposals of many researchers are summarized as follows: Ritter and Speth [1] developed a proposal for a hybrid union of a military ship, between a steel deck and composite superstructure with symmetrical connection is made using an adhesive double joint. This joint was proven by converting two German frigates into yachts. Rudiger and McGeorge [2] developed the symmetrical joint, an adhesive double type with a sandwich panel and without a bevel in connection. The joint was fixed using adhesive and supported by a mechanical fastening.

Hentinen and Hildebrand [3,4] developed an asymmetric single-type adhesive joint with a sandwich panel and transition bevel; the critical load of the joint was absorbed by the bolts. Bohlmann and Fogarty [5] proposed a hybrid joint with bolts, adhesive, and a steel plate that could be welded directly to the deck and screwed or joined to a sandwich-type laminate. Kotsidis, Kouloukouras, and Tsouvalis [6] analyzed the finite elements of a sandwich-type joint, but with a modification, including the inner end of a folded steel plate. Shkolnikov [7] proposed a hybrid joint between steel 
panels and FRP panels; this union has been called 'Comeld-2'. This study focused on the application of composite panels in military and submarine ships. Simler and Brown [8] proposed a US Navy ONR's Navy Joining Center (NJC) adhesive joint consisting of a metal $H$ profile to generate an adhesive double joint, which is to be welded to the deck. The lamination used was vinyl ester resin and a balsa core.

Boyd, Blake, Shenoi, and Kapadia [9] performed a local fatigue analysis on a composite-steel panel, between the joint of the deck and the side of a frigate superstructure. Ozes and Neser [10] conducted experimental tests of hybrid joints between steel and fiber-reinforced panels, using the infusion method, for different roughness states of the steel. Babazadeh and Khedmati [11], in their publication, analyzed the effect of the main parameters of the hybrid joint, sandwich-type with adhesive, through applying tension loads. Johansson [12] and Beeston [13] studied the type of construction used by the Kockums shipyard for the joints of reinforced fiberglass/carbon fiber reinforced polymer (CFRP) superstructures with steel hulls. The panel contact was made on the U profile through adhesives.

The mentioned hybrid joints were applied mainly to join FRP superstructures, masts, and accessories to a metal structure. The proposed joints were mostly of the adhesive type, and a few involved fixing bolts. The methods proposed had some limitations as follows: the difference between the thermal expansion coefficients; the corrosive effect if the steel structure was used; the difficulty of fixing the FRP panel girders to the metal structure; and the fixing of the interface structure to the metal panel. In the present investigation, we used a tubular hybrid joint, as proposed in [14,15], as an option that allowed the following: prefabricating the FRP block, minimizing the difference in the thermal expansion coefficients, and minimizing the corrosive effect due to the metal surfaces that are protected with an adequate epoxy anticorrosive treatment.

Researchers proposed different techniques for the analytical study of adhesive single-lap joints; these methods can be classified as explicit and implicit. Explicit methods to estimate shear and normal stresses (closed form) are as follows: Volkersen [16] was the first to study single adhesive joints, he only proposes the shear stress formula because it does not consider deformations in the adherents. Goland and Reissner [17] propose formulas considering the deformation in the adherents due to the bending moment generated by the eccentricity of the applied force, its method only applies to balanced joints and thin adherents. Hart-Smith [18-22] developed formulas for the stresses considering elastic and plastic adhesive material for balanced and unbalanced joints. Allman [23] developed the formulas for balanced joints considering a non-deformable geometry, concluding that the shear stresses do not vary along with the adhesive. Bigwood and Crocombe $[24,25]$ investigates the shear and normal stresses applicable to various adhesive joint configurations and different adherents, with simplified formulas that are easy to apply. Oplinger [26] following the work of Goland and Reissner, modified the formulas to estimate the stress of the adhesive, considering the thickness of the adhesive and different thicknesses of the adherents. Zou [27] proposed easy-to-apply formulas for estimating adhesive joints only for balanced adherents. These explicit methods are applied for adherents and adhesives with isotropic properties and linear-elastic analysis.

Implicit methods include the following: Renton and Vinson [28] who developed an ordinary linear differential equation of the eighth order, where they consider anisotropic adherents and isotropic adhesive. Ojalvo [29], based on the Goland and Reissner method, analyzed the influence of the thickness of the adhesive on the adhesive joint. Adam and Mallick [30] included the influence of thermal loads on the adhesive bond and the modelling of the spring-loaded adhesive and presented formulas for the stresses on the top and bottom of the adhesive. Smeltzer [31] proposed formulas considering elastic anisotropic adherents and elastic-plastic isotropic adhesive. These methods recommend using numerical methods and/or finite elements depending on the case to complete the estimation of the stresses of the adhesive joints.

The mentioned methods have proposed formulas to statically estimate the stresses and their distribution in the adhesive, however, they have not taken into consideration the behavior of the joint subjected to vibratory loads. These studies are presented by Det Norske Veritas (DNV) [32], 
Hollaway [33], and Huang et al. [34], allowing them to estimate the S-N curve of the joint based on the operating cycles.

In this investigation, the methodology consists of using general formulas to calculate the stresses of adhesive joints applied in a tubular hybrid joint (see Figure 1), and the accomplishment of a failure criterion of interlaminar stresses in the laminates of the adherents. From the different tests performed with finite element analysis (FEA), it was proved that the tubular reinforcement laminate behaves like an adhesive single-lap joint. Bigwood and Crocombe [24] formulas are used due to different thicknesses and stiffness of the adherents of this joint. These formulas have been validated by Nhamoinesu and Overend [35] and Riccio and Sellitto [36] using FEA. Nhamoinesu [35] applied the method to select the epoxy and acrylate adhesive based on the mechanical performance of the bond and subjected to short-duration loads; this analytical method has shown good results with small deformations in the adhesive (30\% of the maximum deformation). However, it loses accuracy with greater deformation compared with the nonlinear FEA results. Riccio [36] apply the Bigwood [24] method as it is of general use in adhesive joints; they used an L-shaped symmetric T-pull model modelled in FEA with four nodes 2D plane elements, finding satisfactory results in the extreme stress values and the distribution along with the adhesive.

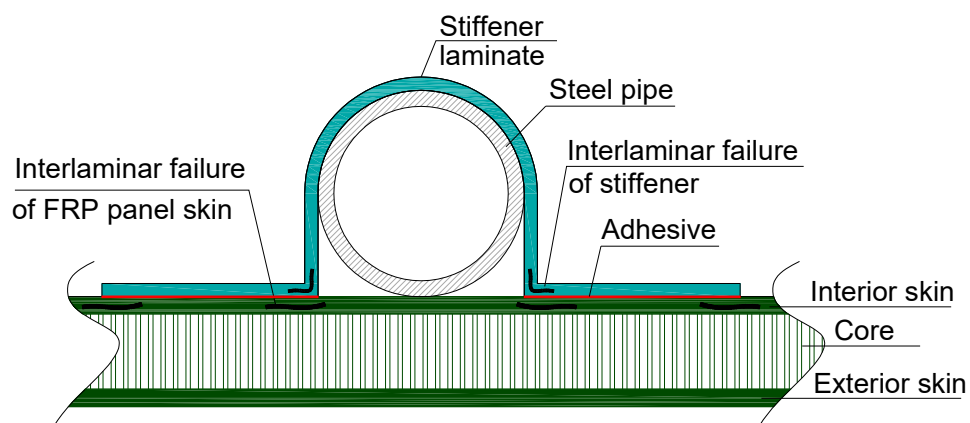

Figure 1. Schematic indicating the typical interlaminar failures in a hybrid joint with tubular reinforcement.

From the results of the different studies, we found that depending on the characteristics of the adhesive joint, the adhesive or the interface between the FRP laminates adherents 1 and 2 may fail [18]. For this reason, when studying a hybrid joint using tubular stiffeners, consideration should be given to the following:

1. The limit of the interlaminar stresses of the adherents, Hou [37].

2. The fatigue on the joint to guarantee its useful life, DNV [32].

For the study of interlaminar stress, the following tubular hybrid joint configuration is considered:

- Adherent 1: fiberglass laminated over the metal pipe.

- Adherent 2: a sandwich panel FRP.

- Adhesive: a 250-micron polyester resin layer.

The orthotropic properties for adherent laminates 1 and 2, are in Appendix A: (Tables A1-A3); the formulas to calculate the 3D stress-strain matrix, the transversal properties of the individual ply, the equivalent isotropic properties, are in Appendix B.

\section{Methodology}

The proposed methodology is used to obtain the resulting stresses at the ends of the adhesive based on the equivalent isotropic properties of adherents 1 and 2 . The simplified formulas proposed by Bigwood/Crocombe [24] to calculate the stresses in the adhesive has the limitation that does not consider the coupling between normal and shear stresses, due to this limitation, the results are useful 
for a preliminary analysis of the tubular hybrid joint. Second, the interlaminar stress analysis in the adherent's adjacent outer layer is carried out, because the properties of the individual ply of the adjacent layers are considered. This part is a localized microstructural analysis to study laminate debonding as a result of fatigue, this debonding is avoided when the quadratic-type failure criterion is met.

\subsection{Proposed Formulas for Tubular Hybrid Joint}

In this section, a mathematical model concerning the behavior of tubular reinforcement on an FRP panel is formulated. For the analysis, we considered that the reinforcement in the panel remains attached by the adhesive.

\subsubsection{Macro-Structural and Microstructural Analysis}

The macro-structural analysis consisted of considering the composite laminate as a monolithic-type solid-elastic body, and allowed a preliminary estimation, based on the following considerations, [38]:

- The structural laminate has a linear behavior; therefore, it complies with Hook's Law [18].

- Transversal deformations due to shear stress are negligible.

- Deformations vary linearly across the thickness.

- The unitary elongation in the vertical direction is considered as being negligible compared to the unitary elongations of the horizontal plane.

- The laminate is quasi-isotropic.

- The formulas for macro-structural analysis are based on the classical theory of plates. The structural laminate panel is considered as being circumscribed and fixed between girders.

The microstructural analysis considered that the layers of the laminate can be approximated with a rectangular laminate stack. This allowed the final estimation of the stresses and deformations of each laminate layer. This type of analysis is also known as a 'critical layer' study.

\subsubsection{Adhesive Model Considerations}

The normal and shear stresses of the adhesive model had the following considerations:

- The Bigwood/Crocombe [24] model considers the adhesive as isotropic, elastic, and linear;

- The adherent's properties are considered isotropic and can be of different thicknesses;

- The adhesive used is polyester resin with the same characteristics of those considered in the Bigwood/Crocombe model [24];

- The adhesive joint of the panel tubular reinforcement is analyzed according to the theory of elasticity;

- A typical diagram of the joint between the reinforcement and the panel is shown in Figure 2;

- $\quad$ The distance $L$ of the joint length;

- The equations of motion are obtained assuming that the panel has a cylindrical flexure behavior.

Equations of Motion in Terms of Normal and Shear Stress, Simplified Analysis

For normal stress, the equation of motion is simplified, based on the consideration that the variation of the shear stress along the joint is lesser in importance [24].

$$
\frac{d^{4} \sigma_{z}}{\partial y^{4}}+4 K_{5}^{4} \sigma_{z}=0
$$

where:

$$
K_{5}^{4}=\frac{E_{a}}{4 \cdot t}\left(\frac{1}{D_{1}}+\frac{1}{D_{2}}\right)
$$


using the following compliance factors for the normal stress calculation:

$$
\begin{aligned}
& \beta_{1}=\frac{12 \cdot E_{a} \cdot\left(1-\mu_{1}^{2}\right)}{E_{1} \cdot h_{1}^{3} \cdot t}, \\
& \beta_{2}=\frac{12 \cdot E_{a} \cdot\left(1-\mu_{2}^{2}\right)}{E_{2} \cdot h_{2}^{3} \cdot t} .
\end{aligned}
$$

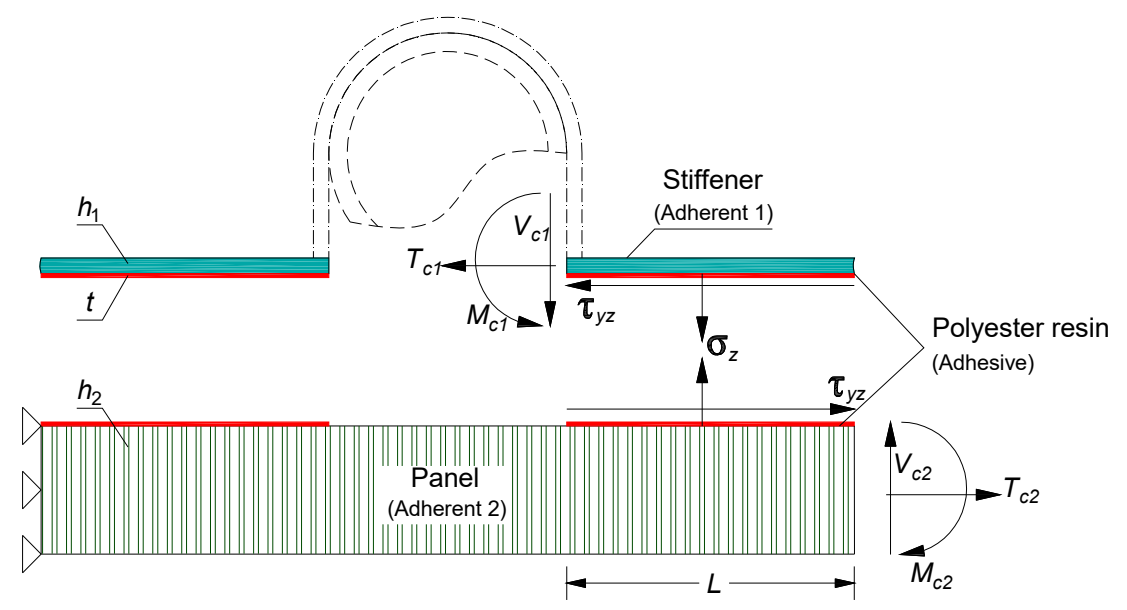

Figure 2. Typical diagram of the stiffener-panel joint.

Based on compliance of these two factors (Equations (3) and (4)), the following formulas are obtained to determine the maximum values of normal stresses:

$$
\begin{gathered}
\sigma_{V_{c}}=\frac{-(2)^{0.5} \cdot \beta_{1} \cdot V_{c}}{\left(\beta_{1}+\beta_{2}\right)^{0.75}} \\
\sigma_{M_{c}}=\frac{-\beta_{1} \cdot M_{c}}{\left(\beta_{1}+\beta_{2}\right)^{0.5}} .
\end{gathered}
$$

For the shear stress, the following motion equation is simplified, based on the assumption that the variation of the normal stress along the joint is small.

$$
\frac{d^{3} \tau_{y z}}{\partial y^{3}}-K_{6}{ }^{2} \frac{d \tau_{y z}}{\partial y}=0,
$$

where:

$$
K_{6}^{2}=\frac{4 \cdot G_{a}}{t}\left(\frac{\left(1-\mu_{1}^{2}\right)}{E_{1} \cdot h_{1}}+\frac{\left(1-\mu_{2}^{2}\right)}{E_{2} \cdot h_{2}}\right),
$$

using the following compliance factors for the calculation of shear stress:

$$
\begin{aligned}
& \alpha_{1}=\frac{G_{a} \cdot\left(1-\mu_{1}^{2}\right)}{E_{1} \cdot h_{1} \cdot t}, \\
& \alpha_{2}=\frac{G_{a} \cdot\left(1-\mu_{2}^{2}\right)}{E_{2} \cdot h_{2} \cdot t} .
\end{aligned}
$$


Based on the compliance of these two factors (Equations (9) and (10)), the following formulas are obtained to determine the maximum values of shear stresses:

$$
\begin{gathered}
\tau_{T_{c}}=\frac{-\alpha_{1} \cdot T_{c}}{2 \cdot\left(\alpha_{1}+\alpha_{2}\right)^{0.5}}, \\
\tau_{V_{c}}=\frac{3 \cdot V_{c}}{4 \cdot h_{1}}, \\
\tau_{M_{c}}=\frac{3 \cdot \alpha_{1} \cdot M_{c}}{h_{1} \cdot\left(\alpha_{1}+\alpha_{2}\right)^{0.5}} .
\end{gathered}
$$

The definition of the variables $V c, T c$, and $M c$ are indicated in Figure 2.

These formulas can be applied to two types of panels the single laminate and the sandwich laminate. Following the model considerations indicated in Section 2.1.2, we expected to estimate the stress to occur in the adhesive.

\subsection{Forces and Moments on the Tubular Hybrid Joint}

The elastic model of Bigwood/Crocombe [24] satisfied the model considerations proposed in Section 2.1.2 and allows us to estimate the adhesive stress of the tubular hybrid joint. To apply these simplified formulas in the tubular hybrid joint, it is necessary to define the forces and moments, as explained below.

In Figure 3, we considered that the reinforcement is subjected to forces $(P, V, T)$ in three directions. In this study, the forces used in the formulas proposed by Bigwood/Crocombe [24] are applied per unit length (see Section 2.1.2 and Appendix C).

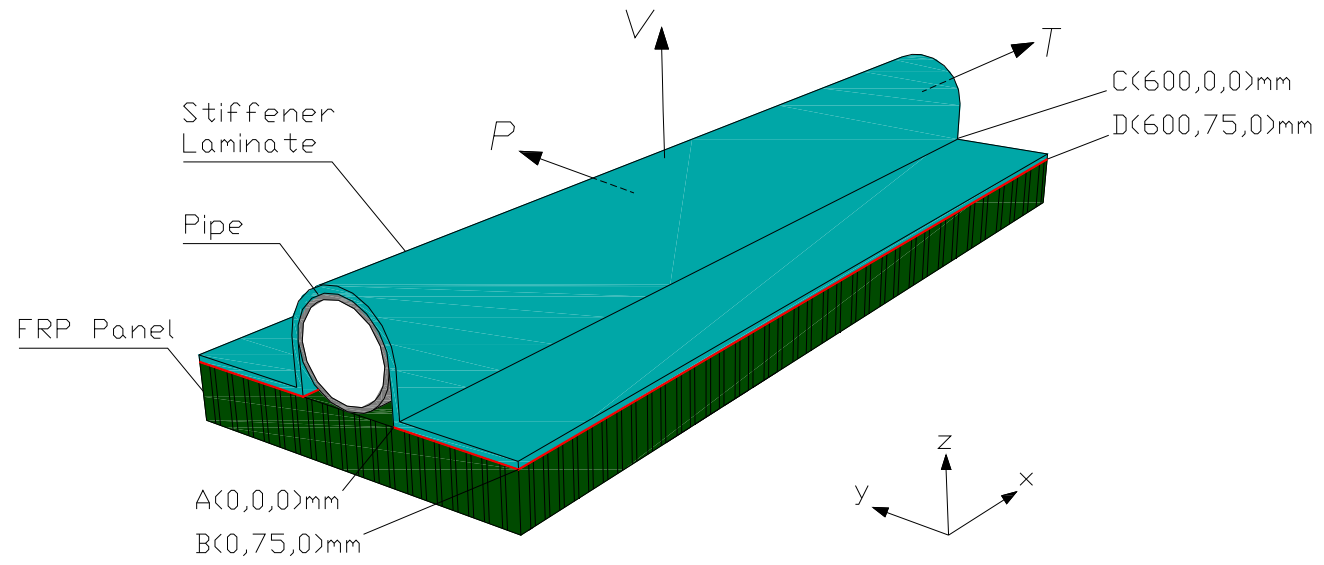

Figure 3. Applied forces on the hybrid joint panel and stiffener.

Where:

- $\quad P$ is the force in the $y$-direction on the hybrid reinforcement; this force generates an equivalent moment $M^{\prime}$ exerted in the tubular laminate. This moment is estimated as follows (see Figure 4):

$$
M^{\prime}=\frac{M}{6}=\frac{P \cdot D}{12}
$$




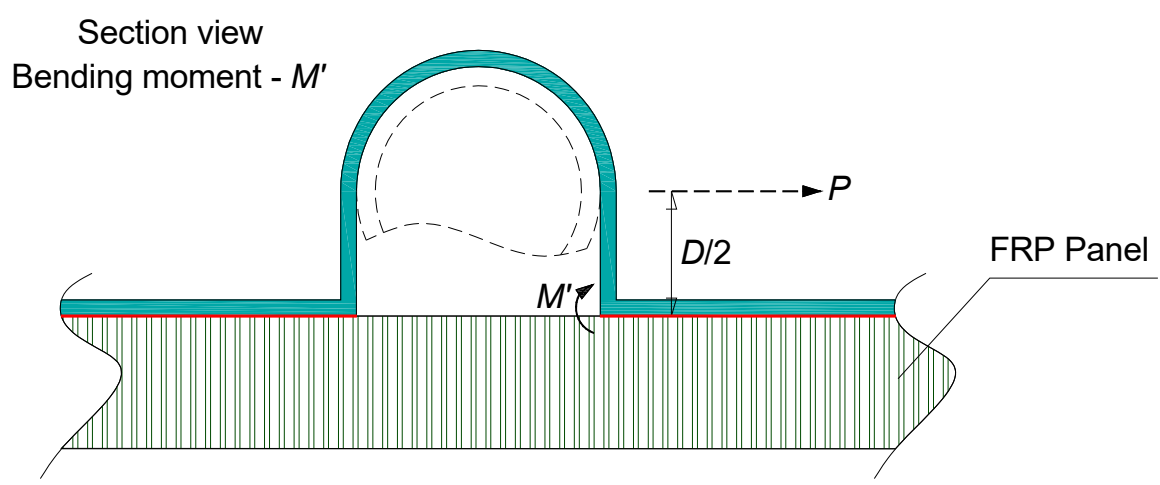

Figure 4. The equivalent moment on the hybrid panel and stiffener.

- $\quad V$ is the force on the hybrid reinforcement in the z-direction. This force is broken into its two components $\left(V_{z}, V_{y}\right)$, separated by the pipe diameter $D$. See Figure 5 a, on both sides of the tubular laminate. The components are defined as follows:

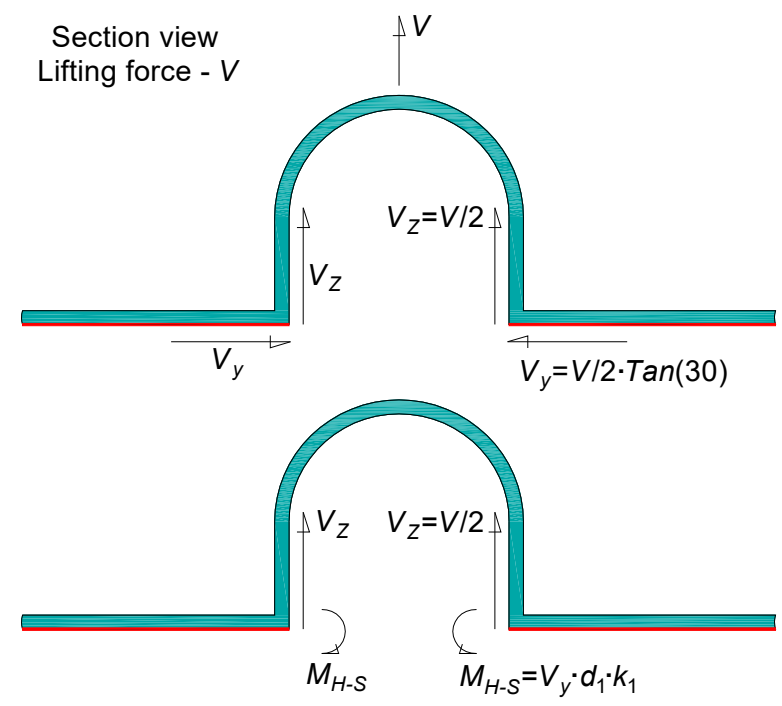

Figure 5. Equivalent lifting forces: (a) vertical force $\mathrm{V}$ decomposition, (b) lifting forces, and moment on the stiffener laminate.

$$
V_{z}=\frac{V}{2}, \quad V_{y}=\frac{V}{2} \cdot \tan (30)
$$

The component $\left(V_{y}\right)$ generates a moment in Adherent 1 . The behavior of the tubular laminate in the $y$-direction is similar to that proposed by Hart-Smith's moment equation [18], see Figure 5b:

$$
M_{H-S}=V_{y} \cdot d_{1} \cdot k_{1}
$$

in which:

$$
\begin{aligned}
& k_{1}=\frac{1}{1+\xi_{1} \cdot c+\frac{\left(\xi_{1} \cdot\right)^{2}}{6}}, \\
& \xi_{1}^{2}=\frac{12 \cdot V_{y} \cdot\left(1-\mu_{1}{ }^{2}\right)}{k_{b} \cdot E_{1} \cdot h_{1}{ }^{3}} .
\end{aligned}
$$

- $T$ is the force applied to the tubular laminate in the $x$-direction; this force is applied to both the laminates and the root to obtain the adhesive shear stress. 
Application to Tubular Hybrid Joint

A typical application of the hybrid tubular joint between a steel deck and FRP panel of a superstructure is presented in Figure 6. The proposed methodology allows estimating the adhesive stresses, so it is necessary to define the forces $(P, V, T)$, these forces must be calculated in advance to be applied over a tubular hybrid joint of the FRP panel, under pressure $p\left(\mathrm{kN} / \mathrm{m}^{2}\right)$.

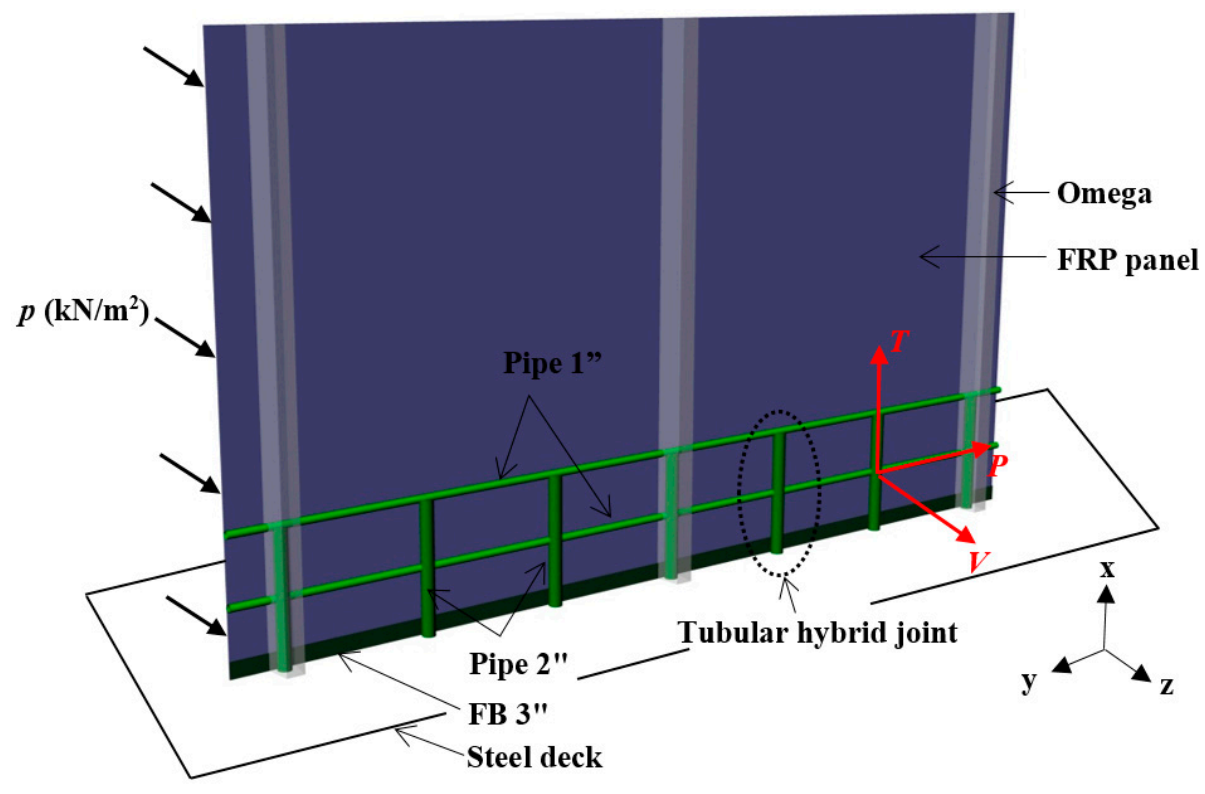

Figure 6. Typical assembly of tubular hybrid joint.

To estimate the resultant forces $(P, V, T)$ on the pipes of the hybrid joint, a global analysis of a superstructure subjected to a pressure $p$ is performed, additionally considering a heeling or pitching. The magnitude of $p$ and the heel or pitch is recommended by the classification society.

In cases where the hybrid joint is installed on the steel deck where there is auxiliary equipment, the moments transferred from the deck to the panel should be added in calculations.

\subsection{Interlaminar Stresses}

\subsubsection{Failure Criteria}

Once the shear and normal adhesive stresses resulting from the applied forces are obtained with equivalent isotropic properties, it is important to evaluate the combination of the interlaminate stresses of the adherent's adjacent outer layer with the properties of the individual ply. The stresses resulting from the Bigwood/Crocombe [24] formulas are considered decoupled by definition. Therefore, the quadratic criterion of Tsai-Hou [37], Equation (17), is selected as the failure criterion.

$$
\sigma_{z} \geq 0, \quad\left(\frac{\sigma_{z}}{Z_{t}}\right)^{2}+\left(\frac{\tau_{x z}^{2}+\tau_{y z}^{2}}{S_{t}^{2}}\right) \geq 1 .
$$

When designing a panel with stiffeners, the type of load to be applied or the fatigue to which it is being subjected must be considered. For this reason, when evaluating the quadratic failure criterion (Equation (17)), the calculated static stresses must be reconsidered as virtual stresses, which includes the type of load to which they are being subjected. These virtual stresses are defined as follows [33]:

$$
\sigma_{z}{ }^{\prime}=\frac{\sigma_{z}}{F_{r c-i}},
$$




$$
\begin{gathered}
\tau_{x z}{ }^{\prime}=\frac{\tau_{x z}}{F_{r c-i}} \\
\tau_{y z}{ }^{\prime}=\frac{\tau_{y z}}{F_{r c-i}} .
\end{gathered}
$$

The modified failure criterion is proposed considering the virtual stresses as indicated:

$$
\sigma_{z} \geq 0, \quad\left(\frac{\sigma_{z}{ }^{\prime}}{Z_{t}}\right)^{2}+\left(\frac{\left(\tau_{x z^{\prime}}\right)^{2}+\left(\tau_{y z^{\prime}}\right)^{2}}{S_{t}{ }^{2}}\right) \geq 1
$$

where:

$$
\sigma_{z} \geq 0, \quad\left(\frac{\sigma_{z}}{F_{r c-i} \cdot Z_{t}}\right)^{2}+\left(\frac{\left(\tau_{x z}\right)^{2}+\left(\tau_{y z}\right)^{2}}{F_{r c-i}{ }^{2} \cdot S_{t}^{2}}\right) \geq 1 .
$$

According to Equations (5), (6), and (11)-(13) applied to the tubular hybrid joint, we considered the following:

$$
\begin{gathered}
\sigma_{z}=\sigma_{M_{c_{-}} P}+\sigma_{V_{c_{-}} V_{z^{\prime}}}, \\
\tau_{x z}=\tau_{T_{c_{-}} T}, \\
\tau_{y z}=\tau_{M_{c_{-}} P}+\tau_{V_{c_{-}} V_{y}} .
\end{gathered}
$$

The formulas indicated are based on linear theory; therefore, the principle of stress superposition can be applied when the resulting stresses are in the same direction. To carry out the optimization process, we considered that not only the first layer must comply with the failure criteria, but all the layers of the laminate including the core must also comply if this is applicable. For this, a matrix must be generated to estimate the behavior of each laminate layer. To estimate the stresses in the successive layers, the formulas proposed by Special Service Craft (SSC) Lloyd's Register [39] can be used to verify that the failure criterion is met.

\subsubsection{Limit Interlaminar Stresses}

The normal and shear stresses' limits in an interlaminate depend on the amount of fiber and the type of resin used. Table 1 shows the limit values of the interlaminar stresses for a laminate with an orthophthalic polyester resin. In the case where one of these parameters is not available, it can be estimated using the following dimensionless relationship (Equation (21b)).

$$
\begin{gathered}
\frac{Z_{t_{1}}}{S_{t_{1}}} \cdot\left(\frac{E_{m 1}}{E_{i 1}}\right)^{1 / 2}=\frac{Z_{t_{2}}}{S_{t_{2}}} \cdot\left(\frac{E_{m 2}}{E_{i 2}}\right)^{1 / 2} \\
Z_{t_{2}}=Z_{t_{1}} \cdot \frac{S_{t 2}}{S_{t 1}} \cdot\left(\frac{E_{m 1}}{E_{m 2}}\right)^{1 / 2} \cdot\left(\frac{E_{i 2}}{E_{i 1}}\right)^{1 / 2}
\end{gathered}
$$

Table 1. Estimation of the failure stresses in the interlaminate.

\begin{tabular}{cccc}
\hline \multirow{2}{*}{ Fiber } & $\mathbf{f}_{\mathbf{c}} \mathbf{( 1 )}^{-1}$ & $S_{\boldsymbol{t}}{ }^{(\mathbf{1})}$ & $Z_{t}$ \\
\cline { 3 - 4 } & & $\mathbf{( M P a )}$ & $\mathbf{( M P a )}$ \\
\hline Uni-directional (UD) & $60 \%$ & 15.00 & $14.60^{(1)}$ \\
Woven Roving (WR) & $50 \%$ & 15.25 & $11.70^{(3)}$ \\
Chopped strand mat (CSM) & $30 \%$ & 17.95 & $9.50^{(3)}$ \\
\hline
\end{tabular}

(1) Lloyd's Register [39], (3) Zt estimated using Equation (21b). Note: see laminate properties $\left(E_{m j}\right.$ y $\left.E_{i j}\right)$, in Appendix A. 
For cases in which the FRP panel is of sandwich-type, with a balsa core, additional consideration must be given to the tensile, compression, and shear stresses of the core, see Lloyd's Register [39]: Table 2.2.2 Minimum characteristics and mechanical properties of end-grain balsa.

\subsubsection{Design Factors: Interlaminar Stress Fraction}

When designing an adhesive hybrid joint, the type of force that the panel is subjected to must be considered to estimate the life of the hybrid joint. Hollaway [33] recommended using the fractions of interlaminated stress for the design of a hybrid joint, depending on the life cycle, see Hollaway [33]: Table 5.2 Typical long term load reduction factors for GFRP: data refer to the ratio of long term strength/short term strength at ambient test conditions.

As a reference, Lloyd's Register [39] recommended using the failure stress fraction for tension or compression stresses [0.3-0.4], and shear stresses [0.33], according to the application area.

\section{Results: Single-Lap Joint Validation by Applying FEA}

The model of a cruising yacht, $36.80 \mathrm{~m}$, proposed in [14] is used for this validation, which consists of applying a design pressure of $5.16 \mathrm{kN} / \mathrm{m}^{2}$ on the side of the first port side deck with an area of $48.78 \mathrm{~m}^{2}$ and a heeling of $30^{\circ}$ to starboard, without considering any moment transmitted from the deck. Resultant forces on an intermediate tubular connection between the omegas are (see Figure 6) $P=134$ [N], $V=5127$ [N], y $T=4899$ [N].

Figure 3 shows the model used for the validation of a tubular hybrid joint, which consists of a $600 \times 210 \times 32.9 \mathrm{~mm}$ FRP panel, a 2" Sch40 steel pipe, and a tubular laminate with four layers of fiberglass over the pipe, the laminate sequence stacking and properties are in Table A2. To apply the formulas in Section 2.1.2 and Appendix C, the equivalent isotropic properties must be estimated from the orthotropic properties (see Appendix B).

\subsection{Numerical Model}

For comparison of results, finite element analysis is performed; 2D and 3D models are developed using Ansys software, considering the orthotropic properties of the laminate in each adherent. A $0.1 \mathrm{~mm}$ polyester resin interface layer is modelled between each layer of the laminates. The 3D model is analyzed with the ACP-Ansys module since it allows entering the properties of the adherents per layer; the adherents are modelled using shell elements and the adhesive using solid elements.

For the 2D model, only the Static Structural module with plain strain configuration is used since it allows analyzing the behavior of laminates and interfaces in the tubular hybrid joint. Software tools for mesh quality analysis are used and the convergence of the stress results with the indicated mesh for the 2D and 3D models, is achieved using a mesh refinement as indicated below:

- Software: Ansys Academic;

Module: ACP Pre, ACP Post and Static Structural;

- Meshing 3D: Model size $600 \mathrm{~mm}$, general mesh $4 \mathrm{~mm}$, refinement to $1.5 \mathrm{~mm}$ on a $30 \mathrm{~mm}$ radius on pipe corners, and to $0.2 \mathrm{~mm}$ on the middle panel on a $10 \mathrm{~mm}$ radius. The adhesive has three elements through-thickness, (see Figure 7a);

Nodes: 69,367;

Element: Quadrilateral Dominant;

- Meshing 2D: Model size $210 \mathrm{~mm}$, general mesh $0.7 \mathrm{~mm}$ and refinement to $0.15 \mathrm{~mm}$ on a $6 \mathrm{~mm}$ radius on adhesive ends. The adhesive has two elements through-thickness, (see Figure 7b);

Nodes: 99,482;

- Element: Quadrilateral Dominant. 
- Modeling: The metal pipe is not considered in the validation.

- Boundary conditions: The panel is considered as being simply supported in the $(x, y, z)$ directions, at the ends of the panel (adherent 2). The tubular laminate (adherent 1 ) is considered as being free at its ends.

- Forces:

For the $x$-direction $(T)$ :

- The force is applied, taking into consideration the entire laminate surface of the reinforcement excluding the bonding tubular laminate over the panel.

$\bigcirc \quad$ For the $y$-direction $(P)$ :

- The force is applied on the side of the tubular laminate at a remote point in the center of the metal pipe.

For the z-direction $(V)$ :

- The force is applied, taking into consideration the entire laminate surface of the reinforcement excluding the bonding tubular laminate over the panel.
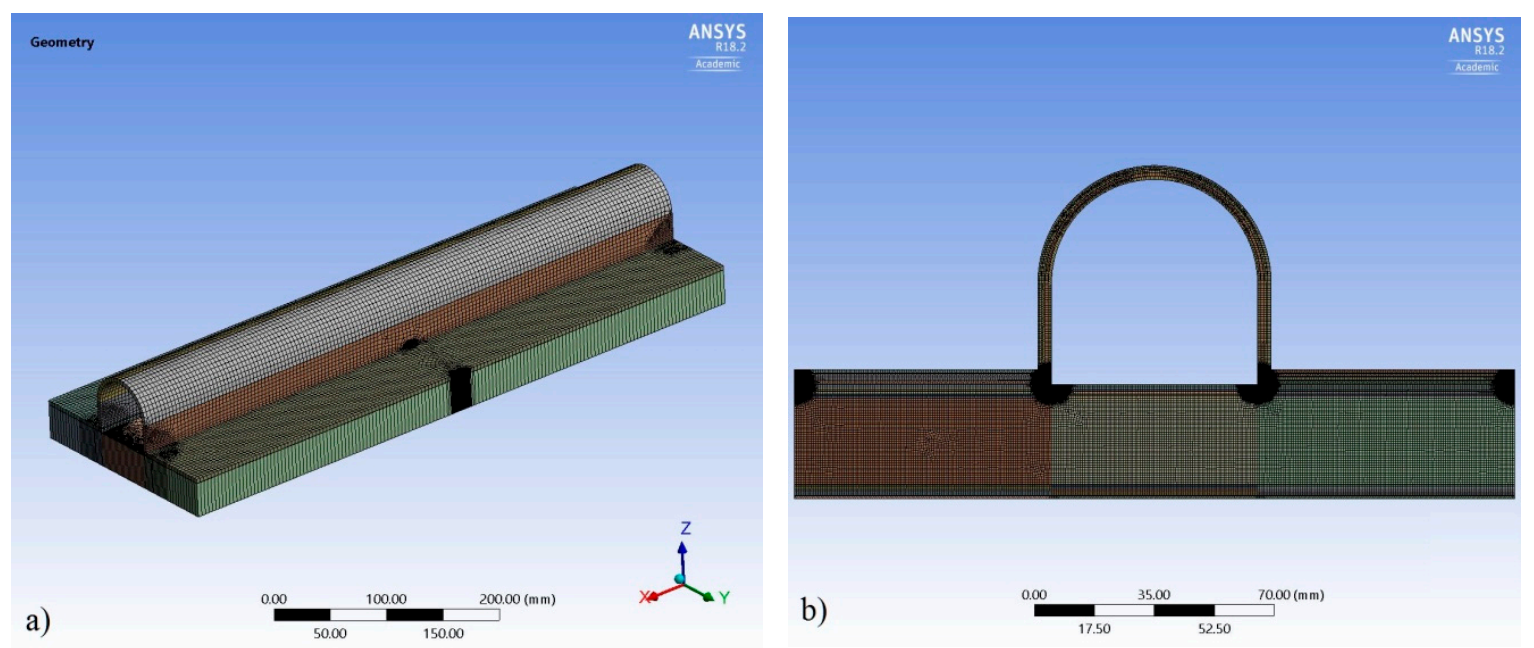

Figure 7. (a) 3D model: fiber-reinforced plastic (FRP) panel $210 \times 600 \mathrm{~mm}$, with 2 " pipe laminate, (b) 2D model: FRP Panel $210 \mathrm{~mm}$ by unitary width, with 2" pipe laminate.

\subsection{Results}

The following Figures 8-10 present the comparison of stresses obtained from 2D, 3D FEA models and the general formulas of Bigwood and Crocombe [24] presented in Appendix C. The stress curves of formulas [24] show similar behaviors to the results obtained with the numerical analysis (FEA), however, the normal stress generated by the $T$ force (Figure 8a) is zero.

The distribution of the maximum shear stresses of the $T$ force, from the $3 \mathrm{D}$ model, at the first interface stress distribution between layers 1 and 2 of adherent 1 is presented in Figure 11.

The distribution of normal and shear stresses on adhesive and adherent 1 interfaces resulting from the $V$ force, 2D model, are presented in Figure 12.

The results obtained in the adhesive at the endpoints A and B (Figure 3) with the proposed normal and shear stress formulas, and stresses calculate with FEA are presented in Tables 2 and 3 corresponding to the forces $P, V$, and $T$. Only results are presented in points $\mathrm{A}$ and $\mathrm{B}$ because they have greater values than points $C$ and $D$. These tables present the application of the failure criterion (Equation (19b)), showing that the criterion is met. 

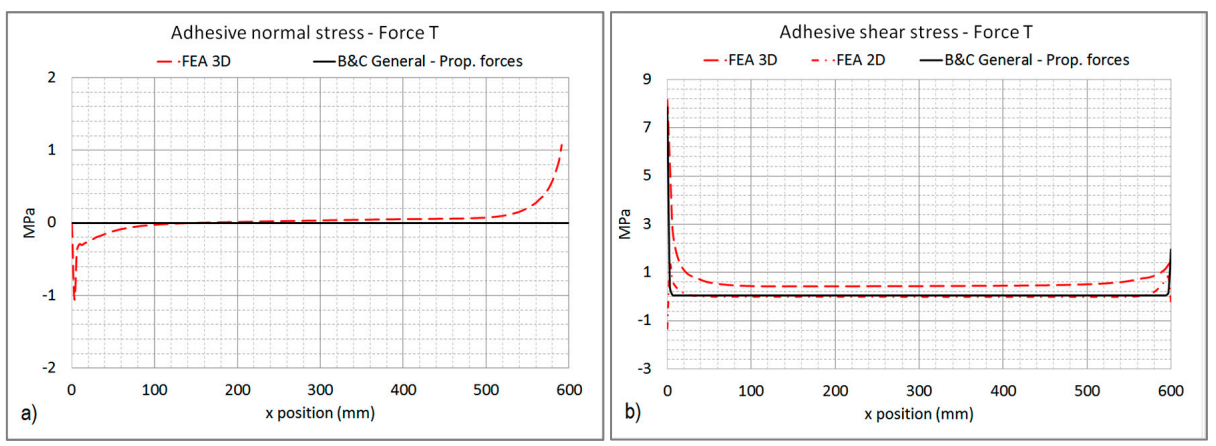

Figure 8. Force T, $x$-direction: stress curve, (a) normal, (b) shear.
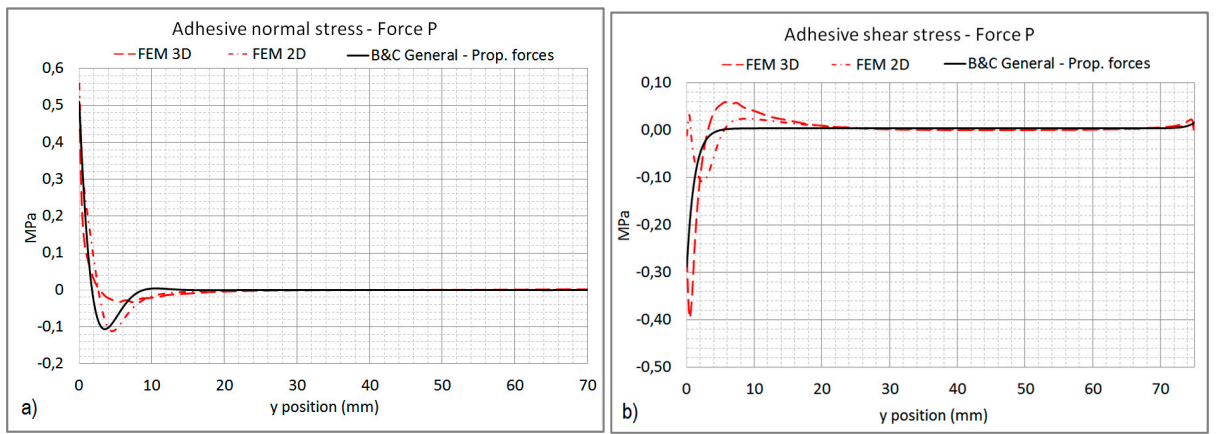

Figure 9. Force $P, y$-direction: stress curve, (a) normal, (b) shear.
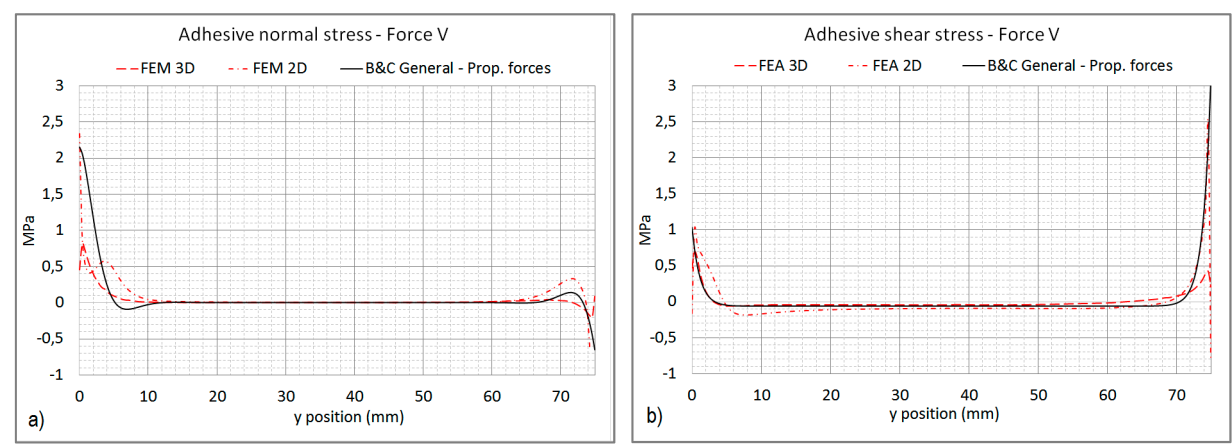

Figure 10. Force V, $z$-direction: stress curve, (a) normal, (b) shear.

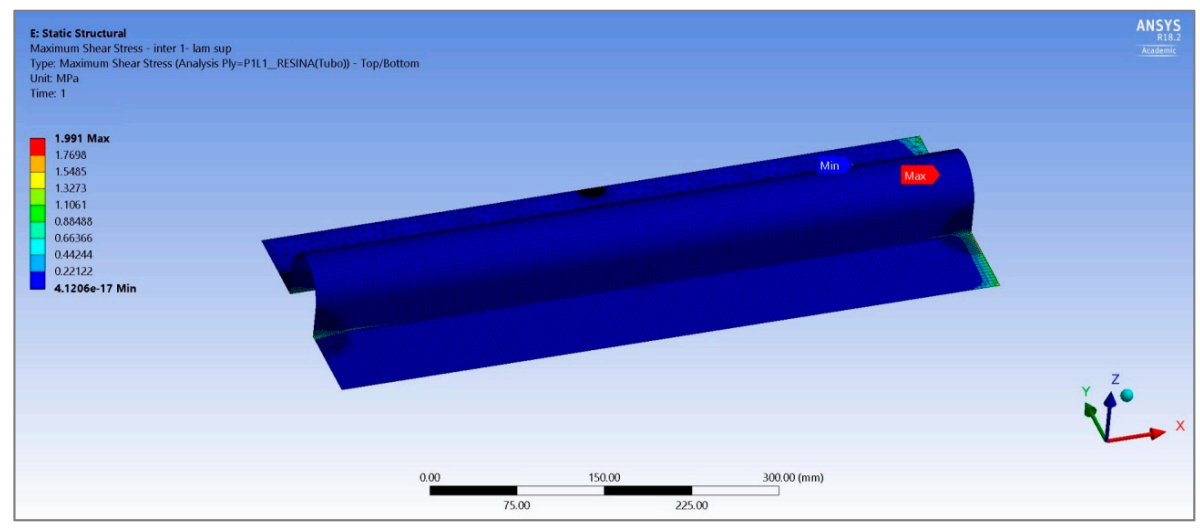

Figure 11. Force T, $x$-direction, from the 3D model: first interface stress distribution between layers 1 and 2 of adherent 1 . 

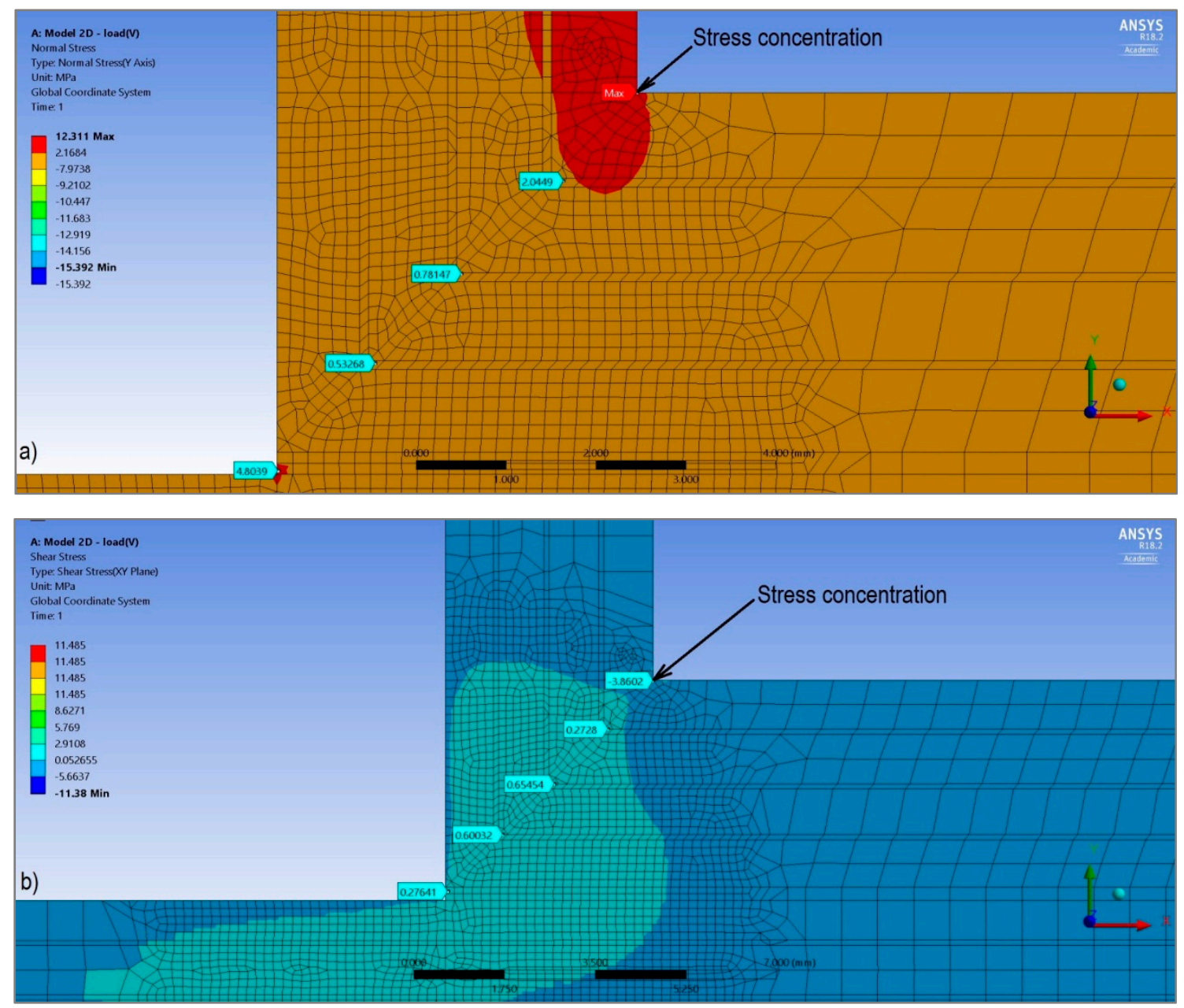

Figure 12. Force $V$, $z$-direction, from the $2 \mathrm{D}$ model: stress distribution, (a) normal, (b) shear.

Table 2. Failure criteria the tubular hybrid joint: Bigwood and Crocombe formulas.

\begin{tabular}{|c|c|c|c|c|c|c|c|}
\hline \multirow{4}{*}{ Variable } & \multirow{4}{*}{ Value } & \multicolumn{6}{|c|}{ Bigwood and Crocombe Formulas } \\
\hline & & \multicolumn{3}{|c|}{ A $(0,0,0) \mathrm{mm}$} & \multicolumn{3}{|c|}{ B $(0,75,0) \mathrm{mm}$} \\
\hline & & \multirow{2}{*}{$\begin{array}{c}\begin{array}{c}\sigma \\
(\mathrm{MPa})\end{array} \\
\mathrm{z}\end{array}$} & \multicolumn{2}{|c|}{$\begin{array}{c}\tau \\
(\mathrm{MPa})\end{array}$} & \multirow{2}{*}{$\begin{array}{c}\begin{array}{c}\sigma \\
(\mathrm{MPa})\end{array} \\
\mathrm{z}\end{array}$} & \multicolumn{2}{|c|}{$\begin{array}{c}\tau \\
(\mathrm{MPa})\end{array}$} \\
\hline & & & yz & $\mathbf{x z}$ & & yz & $\mathbf{x z}$ \\
\hline$T(\mathrm{~N} / \mathrm{mm})$ & 4899 & 0.000 & - & 7.858 & 0.000 & - & 7.858 \\
\hline$V(\mathrm{~N} / \mathrm{mm})$ & 5127 & 2.148 & 1.031 & - & -0.652 & 3.076 & - \\
\hline$P(\mathrm{~N} / \mathrm{mm})$ & 134 & 0.509 & -0.287 & - & -0.003 & 0.016 & - \\
\hline \multicolumn{2}{|c|}{$\sigma_{z}(\mathrm{MPa})$} & 2.657 & - & - & -0.655 & - & - \\
\hline \multicolumn{2}{|c|}{$\tau_{y z}(\mathrm{MPa})$} & - & 0.744 & - & - & 3.092 & - \\
\hline \multicolumn{2}{|c|}{$\tau_{x z}(\mathrm{MPa})$} & - & - & 7.858 & - & - & 7.858 \\
\hline \multicolumn{2}{|c|}{$\mathrm{Z}_{t}(\mathrm{MPa})$} & \multicolumn{3}{|c|}{9.500} & \multicolumn{3}{|c|}{9.500} \\
\hline \multicolumn{2}{|c|}{$S_{t}(\mathrm{MPa})$} & \multicolumn{3}{|c|}{17.950} & \multicolumn{3}{|c|}{17.950} \\
\hline \multicolumn{2}{|c|}{$\begin{array}{l}\text { Interlaminar Stress } \\
\text { Fraction, } F_{r c-i}\end{array}$} & \multicolumn{3}{|c|}{0.650} & \multicolumn{3}{|c|}{0.650} \\
\hline \multicolumn{2}{|c|}{ Failure Criteria } & \multicolumn{3}{|c|}{0.500} & \multicolumn{3}{|c|}{0.510} \\
\hline
\end{tabular}


Table 3. Failure criteria the tubular hybrid joint: FEA.

\begin{tabular}{|c|c|c|c|c|c|c|c|}
\hline \multirow{4}{*}{ Variable } & \multirow{4}{*}{ Value } & \multicolumn{6}{|c|}{ FEA } \\
\hline & & \multicolumn{3}{|c|}{ A $(0,0,0) \mathrm{mm}$} & \multicolumn{3}{|c|}{ B $(0,75,0) \mathrm{mm}$} \\
\hline & & \multirow{2}{*}{$\begin{array}{c}\begin{array}{c}\sigma \\
(\mathrm{MPa})\end{array} \\
\mathrm{z}\end{array}$} & \multicolumn{2}{|c|}{$\begin{array}{c}\tau \\
(\mathrm{MPa})\end{array}$} & \multirow{2}{*}{$\begin{array}{c}\begin{array}{c}\sigma \\
(\mathrm{MPa})\end{array} \\
\mathrm{z}\end{array}$} & \multicolumn{2}{|c|}{$\begin{array}{c}\tau \\
(\mathrm{MPa})\end{array}$} \\
\hline & & & yz & $\mathbf{x z}$ & & yz & $\mathbf{x z}$ \\
\hline$T(\mathrm{~N} / \mathrm{mm})$ & 4899 & -0.006 & - & 8.152 & -0.006 & - & 8.152 \\
\hline$V(\mathrm{~N} / \mathrm{mm})$ & 5127 & 2.330 & 1.020 & - & -0.610 & 2.480 & - \\
\hline$P(\mathrm{~N} / \mathrm{mm})$ & 134 & 0.493 & -0.393 & - & -0.014 & 0.023 & - \\
\hline \multicolumn{2}{|c|}{$\sigma_{z}(\mathrm{MPa})$} & 2.817 & - & - & -0.629 & - & - \\
\hline \multicolumn{2}{|c|}{$\tau_{y z}(\mathrm{MPa})$} & - & 0.627 & - & - & 2.503 & - \\
\hline \multicolumn{2}{|c|}{$\tau_{x z}(\mathrm{MPa})$} & - & - & 8.152 & - & - & 8.152 \\
\hline \multicolumn{2}{|c|}{$Z_{t}(\mathrm{MPa})$} & & 9.500 & & & 9.500 & \\
\hline \multicolumn{2}{|c|}{$S_{t}(\mathrm{MPa})$} & & 17.950 & & & 17.950 & \\
\hline \multicolumn{2}{|c|}{$\begin{array}{c}\text { Interlaminar Stress } \\
\text { Fraction, } F_{r c-i}\end{array}$} & \multicolumn{3}{|c|}{0.650} & \multicolumn{3}{|c|}{0.650} \\
\hline \multicolumn{2}{|c|}{ Failure Criteria } & \multicolumn{3}{|c|}{0.540} & \multicolumn{3}{|c|}{0.520} \\
\hline
\end{tabular}

Using the formulas of the failure criterion it is possible to obtain the limit values of the safety factor $S_{f}$ and the design pressure $p$ that the adhesive joint can withstand. Table 4 presents the limit design pressure $p$, keeping constant interlaminar stress fraction at 0.650 . Similarly, Table 5 presents as an alternative to the maximum safety factor $S_{f}$ to which this FRP panel can be subjected, maintaining a constant design pressure of $5.160 \mathrm{kN} / \mathrm{m}^{2}$. These indicated limit values of $p$ and $S_{f}$ application are subject to compliance of the critical layer analysis of FRP panel proposed by SSC-Lloyd's Register, [39].

Table 4. Design limit pressure using the failure criteria.

\begin{tabular}{|c|c|c|c|}
\hline & Pressure Factor & $\begin{array}{l}\text { Design Pressure, } p \\
\left(\mathrm{kN} / \mathrm{m}^{2}\right)\end{array}$ & Failure Criterion \\
\hline$p$ (initial) & 1.000 & 5.160 & 0.540 \\
\hline$p$ (maximum) & 1.360 & 7.030 & 1.000 \\
\hline
\end{tabular}

Table 5. Safety factor using the failure criteria.

\begin{tabular}{ccc}
\hline & Safety Factor & Failure Criterion \\
\hline $\mathrm{F}_{\mathrm{rc}-\mathrm{i}}($ initial $)$ & 1.540 & 0.540 \\
$\mathrm{~F}_{\mathrm{rc}-\mathrm{i}}$ (minimum) & 2.080 & 1.000 \\
\hline
\end{tabular}

The safety factor $S_{f}$ is defined as:

$$
S_{f}=\frac{1}{F_{r c-i}}
$$

\section{Discussion}

The method proposed by Bigwood and Crocombe includes simplified and general formulas that allow knowing the maximum and distributed values of the normal and shear stresses along with the adhesive. The results obtained with both formulations result in similar values and simplified formulas allow the quick estimation and easy application.

2D and 3D models have the same boundary conditions, making it possible to make a comparison between the results of the stresses. The $2 \mathrm{D}$ model is made for a local analysis allowing a more refined mesh; the stress distribution results obtained demonstrate a slight difference in their extreme values of the adhesive, attributed to boundary singularities of the model. 
Figure 8a shows that applying a horizontal force $(T)$, the Bigwood and Crocombe formulas do not calculate the normal stress, however, the FEA model shows the normal stress.

Regarding the points defined in Figure 3, it can be shown in Figure 10 that when the force $V$ is applied at point $\mathrm{A}$, there is a shear stress value of $1.031 \mathrm{MPa}$, while at the extreme point $\mathrm{B}$ the shear stress is $3.076 \mathrm{MPa}$, this difference in stress is due to the moment reaction generated at the boundary condition in the adherent 2 .

In Figures 11 and 12, the behavior of the stresses through the laminate and its interfaces is shown. The stresses of the adhesive are like those presented in the first interface of the adherents 1 and 2, therefore the thickness of the interface and the adhesive of the joint must be considered.

In Figure 12 of the 2D model, high-stress values are presented in the corner of the external laminate of the adherent 1 due to the stress concentration in this corner.

A tubular hybrid joint (see Figure 6) can be optimized based on the number of layers of the tubular laminate, configuration of the tubular structure, and the limit pressure that the FRP panel and the hybrid tubular joint can support. In cases where it is required to increase the pressure $p$, the FRP panel laminate should be reviewed utilizing critical layer analysis, and as an option closer vertical pipes can be installed.

\section{Conclusions}

Initially, for the preliminary design, the macro-structural analysis should be carried out on the scantling of the panel structure, using a Classification Society guideline. Then, a microstructural analysis of the laminate sequence should be carried out using a "critical layer" analysis. Finally, the hybrid tubular joint is dimensioned as an additional reinforcement of the panel, according to the forces acting on the hybrid joint.

The number of laminate layers on the tubular reinforcements depends on the type of design load that are applied or transmitted to the panel and/or tubular hybrid joint; thus, the laminate scantling should be validated by the failure criteria using the interlaminar stresses.

The model considerations are applicable for the interlaminar study but do not include the calculation of the temperature or hygroscopic effects. Another aspect is the tubular laminate bevelling, as the maximum resulting stresses are located at the reinforced laminate ends. For this reason, we recommend that the bevel guide proposed by SSC-Lloyd's Register be applied.

The proposed moment formula is recommended for tubular reinforcement. In the case where it is necessary to apply another structural reinforcement type, the formula must be modified, the compatibility and stresses between laminates should be analyzed.

The interlaminar stresses resulting from the outer layer are related to the possibility of debonding; however, in the case of sandwich panels as a second stage, we recommend analyzing the interlaminar and intralaminar stresses of all layers and the core. In no case, the core should be used perpendicular to the stress direction.

When comparing the interlaminar stress fraction recommended by SSC-Lloyd's Register with that proposed by Hollaway, this fraction corresponds to $10^{6}$ lifecycles, assuming that the core tie layer is CSM. Additionally, Hollaway proposed that the fraction may also have lower values than those recommended by SSC-Lloyd's Register, depending on the fatigue applied. For this reason, we recommend researching the variation of the interlaminar stress fraction as a function of fatigue.

The formulas proposed for the shear and normal stress estimation showed satisfactory results when compared with the values obtained with FEA. The proposed methodology made possible the study of the behavior of the stresses obtained at the adhesive ends and the analysis of the resulting interlaminar stresses that are generated in the adherent's adjacent outer layer. The stress analysis in of the remaining layers and the interlaminar effect on the core, is beyond the scope of this investigation, however, is an important topic of study in the future. For the proposed equations, the failure stresses for laminates of polyester resin with E fiberglass (FRP) are presented in Table 1. 
The proposed methodology is aimed to facilitate the preliminary design of a tubular hybrid joint. The joint as designed allows to join the FRP panel with metal decks having the advantage of getting a watertight union, improving the contact area of the adhesive, and obtaining an inert hybrid metal structure, having as an additional advantage that, depending on the type of load condition on the FRP panel and steel deck, it is easy to increase the number of vertical reinforcements or the adhesive joint length.

Author Contributions: F.D.: introduction, summary, writing, methodology, tables, figures, validation of results, discussion. L.C.: work structure, discussion of results and conclusions. All authors have read and agreed to the published version of the manuscript.

Funding: This research received no external funding

Acknowledgments: The authors thank the ESPOL Polytechnic University, Escuela Superior Politécnica del Litoral, Faculty of Maritime Engineering and Marine Sciences (FIMCM), for the facilities provided with the laboratory.

Conflicts of Interest: The authors declare that they have no known competing for financial interests or personal relationships that could have appeared to have influenced the work reported in this paper.

\section{Nomenclature}

$A_{i j} \quad$ Extensional stiffness matrix

$c \quad$ Half-length of adhesive

C Contiguity factor, Ueruma

D Tubular reinforcement diameter

$d_{1} \quad$ Distance from the neutral axis of adhesive to

$d_{1} \quad$ the applied load

$D_{1} \quad$ Adherent 1 rigidity

$\mathrm{D}_{2} \quad$ Adherent 2 rigidity

$E_{\mathrm{a}} \quad$ Adhesive elasticity modulus

$E_{f} \quad$ Elasticity modulus of the fibers

$E_{i j} \quad$ Elasticity modulus of individual ply $E_{i 1}$ y $E_{i 2}$, Equation (21a)

$E_{i}{ }^{i-p} \quad$ Elasticity modulus of individual ply: $E_{x}, E_{y}$ and $E_{z}$, Table A1

$E_{i} \quad$ Elasticity modulus of adherent laminate: $E_{x}, E_{y}$ and $E_{z}$, Table A2

$E_{\mathrm{mj}} \quad$ Elasticity modulus of the resin $E_{m 1}$ y $E_{m 2}$,

$E_{\text {mj }} \quad$ Equation (21a)

$E_{\mathrm{m}} \quad$ Elasticity modulus of the resin

$E_{1} \quad$ Adherent 1 elasticity modulus, Table A3

$E_{2} \quad$ Adherent 2 elasticity modulus, Table A3

$f_{c} \quad$ Fiber content of individual ply

$F_{r c-i} \quad$ Interlaminar stress fraction

$G_{a} \quad$ Adhesive shear modulus

$G_{i}^{i-p} \quad$ Shear modulus of individual ply: $G_{x}, G_{y}$ and $G_{z}$,Table A1
$S_{t} \quad$ Shear interlaminar stress limit

$t \quad$ Adhesive thickness

$T \quad x$-direction force on tubular reinforcement laminate $y$-direction force on the adhesive joint,

$T_{\mathcal{C}} \quad$ for Bigwood formulation z-direction force on tubular reinforcement laminate

$V_{f} \quad$ Volume fraction of fibers of individual ply

$V_{m} \quad$ Volume fraction of resin $y$ direction components of force $V$ on tubular reinforcement laminate $z$ direction components of force $V$ on tubular reinforcement laminate $\mathrm{z}$-direction force on the adhesive joint, for Bigwood formulation

Longitudinal direction

Transverse direction

Vertical direction

$Z_{t} \quad$ Normal interlaminar stress limit

$\alpha_{1} \quad$ Adherent compliance factor 1 for shear stress, Bigwood formulation

Adherent compliance factor 2, Bigwood formulation

Adherent compliance factor 1 for normal stress, Bigwood formulation

Adherent compliance factor 2 for normal stress, Bigwood formulation Exponent of the tension distribution of flexure in the adherent, Hart-Smith

$\varepsilon_{i}, \varepsilon_{i j} \quad$ Mid-surface strains 
$G_{i} \quad$ Shear modulus of adherent laminate: $G_{x}, G_{y}$ and $G_{z}$,Table A2

$G_{f} \quad$ Shear modulus of the fibers

$G_{m} \quad$ Shear modulus of the resin

$h_{k} \quad$ Thickness of individual ply

$h_{1} \quad$ Adherent 1 thickness

$h_{2} \quad$ Adherent 2 thickness

$k_{1} \quad$ Eccentricity factor, Hart-Smith

$k_{b} \quad$ Parameter of flexural stiffness for compound

$k_{b} \quad$ adherents, Hart-Smith

$K_{5}$

Constant of tension differential equations of normal stress, Bigwood formulation

$K_{6}$

Constant of tension differential equations of shear stress, Bigwood formulation

$L \quad$ Length of adhesive, $L=2 \cdot c$

$M_{c} \quad$ X-moment on the adhesive joint, Bigwood

$M_{\mathcal{C}} \quad$ formulation

$M^{\prime}$

Equivalent moment on tubular reinforcement laminate

$M_{H-S} \quad$ Adhesive joint moment, Hart-Smith

$\bar{Q}_{i j} \quad$ Lamination parameter, Appendix B.1.1

$p \quad$ Design pressure $\mathrm{kN} / \mathrm{m}^{2}$

$P \quad y$-direction force on tubular reinforcement

$P \quad$ laminate

$S_{f} \quad$ Safety factor
$\sigma_{T c}$

$\sigma_{V c}$

$\sigma_{M c}$

$\sigma_{z}$

$\mu_{i}^{i-p}$

$\mu_{i}$

$\mu$

$\mu_{f}$

$\mu_{m}$

$\mu_{1}$

$\mu_{2}$

$\tau_{y z}$

$\tau$

$\tau_{x z}$

$\tau_{\mathrm{Tc}}$

$\tau_{V c}$

$\tau_{M c}$

$\zeta_{f}$

$\zeta_{R}$
Density $\mathrm{kg} / \mathrm{m}^{3}$

Normal interlaminar stress due to axial force $\left(T_{c}\right)$, Bigwood formulation

Normal interlaminar stress due to shear force $\left(V_{c}\right)$, Bigwood formulation

Normal interlaminar stress due to moment $\left(M_{\mathcal{C}}\right)$, Bigwood formulation Total normal interlaminar stress Poisson coefficient of individual ply: $\mu_{x}$, $\mu_{y}$ and $\mu_{z}$, Table A1

Poisson coefficient of adherent laminate: $\mu_{x}, \mu_{y}$, and $\mu_{z}$, Table A2

Poisson coefficient for the fiber

Poisson coefficient for the resin

Adherent 1 Poisson coefficient

Adherent 2 Poisson coefficient

Total shear interlaminar stress on yz direction

Total shear interlaminar stress on $\mathrm{xz}$ direction

Shear interlaminar stress due to axial force $\left(T_{c}\right)$

Shear interlaminar stress due to shear force $\left(V_{c}\right)$

Shear interlaminar stress due moment $\left(M_{c}\right)$

Specific gravity of fiber in individual ply

Specific gravity of resin in individual ply

\section{Abbreviations}

$\begin{array}{ll}\text { CSM } & \text { Chopped strand mat (fiberglass) } \\ \text { CFRP } & \text { Carbon fiber reinforced polymer } \\ \text { DNV } & \text { Det Norske Veritas } \\ \text { FEA } & \text { Finite element analysis } \\ \text { FRP } & \text { Fiber-reinforced plastic } \\ \text { NJC } & \text { US Navy ONR's Navy Joining Center } \\ \text { SSC } & \text { Special Service Craft } \\ \text { UD } & \text { Uni-directional fiber } \\ \text { WR } & \text { Woven Roving (Fiberglass) }\end{array}$

\section{Appendix A}

Input Data, Properties of Fiber, Resin, and Core

Properties on (xy) plane of fibers, core, and resin are defined using Lloyd's Register [39] guidelines. Properties of transversal planes $(y z$ and $x z)$ are estimated with formulas of Appendix B. 
Table A1. Fibers, resin, and core properties for individual ply.

\begin{tabular}{lcccccc}
\hline \multicolumn{1}{c}{ Properties } & Symbol & CSM 300 & CSM 450 & WR 800 & Balsa & Polyester Resin \\
\hline Density $\left(\mathrm{kg} / \mathrm{m}^{3}\right)$ & $\rho$ & 1384 & 1428 & 1634 & 144 & 1200 \\
Elasticity modulus $x$-direction $\left(\mathrm{N} / \mathrm{mm}^{2}\right)$ & $E_{x}{ }^{i-p}$ & 5750 & 6500 & 14,500 & 67.80 & 3400 \\
Elasticity modulus y-direction $\left(\mathrm{N} / \mathrm{mm}^{2}\right)$ & $E_{y}{ }^{2-p}$ & 5750 & 6500 & 14,500 & 67.80 & 3400 \\
Elasticity modulus z-direction $\left(\mathrm{N} / \mathrm{mm}^{2}\right)$ & $E_{z}{ }^{i-p}$ & 4169 & 4414 & 6017 & 3900 & 3400 \\
Shear modulus xy-direction $\left(\mathrm{N} / \mathrm{mm}^{2}\right)$ & $G_{x y}{ }^{i-p}$ & 2665 & 2750 & 3090 & 19 & 1250 \\
Shear modulus xz-direction $\left(\mathrm{N} / \mathrm{mm}^{2}\right)$ & $G_{x z}{ }^{2-p}$ & 1607 & 1713 & 2364 & 129 & 1250 \\
Shear modulus yz-direction $\left(\mathrm{N} / \mathrm{mm}^{2}\right)$ & $G_{y z}{ }^{2-p}$ & 1607 & 1713 & 2364 & 129 & 1250 \\
Poisson coefficient xy & $\mu_{x y}{ }^{i-p}$ & 0.340 & 0.340 & 0.320 & 0.285 & 0.360 \\
Poisson coefficient xz & $\mu_{x z}{ }^{i-p}$ & 0.340 & 0.330 & 0.300 & 0.014 & 0.360 \\
Poisson coefficient yz & $\mu_{y z}{ }^{i-p}$ & 0.340 & 0.330 & 0.300 & 0.014 & 0.360 \\
\hline
\end{tabular}

Table A2 presents the orthotropic properties for the adherent's laminates 1 and 2, calculated with the formulas indicated in Appendix B.1.1.

Table A2. Orthotropic properties of adherents.

\begin{tabular}{lccc}
\hline \multicolumn{1}{c}{ Properties } & Symbol & Adherent 1 & Adherent 2 \\
\hline Density $\left(\mathrm{kg} / \mathrm{m}^{3}\right)$ & $\rho$ & 1513 & 499 \\
Thickness $(\mathrm{mm})$ & $h$ & 4.030 & 32.900 \\
Elasticity modulus $x$-direction $\left(\mathrm{N} / \mathrm{mm}^{2}\right)$ & $E_{x}$ & 8569 & 2064 \\
Elasticity modulus $y$-direction $\left(\mathrm{N} / \mathrm{mm}^{2}\right)$ & $E_{y}$ & 8569 & 2064 \\
Elasticity modulus z-direction $\left(\mathrm{N} / \mathrm{mm}^{2}\right)$ & $E_{z}$ & 5119 & 4249 \\
Shear modulus xy-direction $\left(\mathrm{N} / \mathrm{mm}^{2}\right)$ & $G_{x y}$ & 2713 & 652 \\
Shear modulus xz-direction $\left(\mathrm{N} / \mathrm{mm}^{2}\right)$ & $G_{x z}$ & 1770 & 166 \\
Shear modulus yz-direction $\left(\mathrm{N} / \mathrm{mm}^{2}\right)$ & $G_{y z}$ & 1770 & 166 \\
Poisson coefficient xy & $\mu_{x y}$ & 0.421 & 0.421 \\
Poisson coefficient xz & $\mu_{x z}$ & 0.490 & 0.170 \\
Poisson coefficient yz & $\mu_{y z}$ & 0.490 & 0.170 \\
Poisson coefficient yx & $\mu_{y x}$ & 0.421 & 0.421 \\
Poisson coefficient zx & $\mu_{z x}$ & 0.293 & 0.349 \\
Poisson coefficient zy & $\mu_{z y}$ & 0.293 & 0.349 \\
\hline
\end{tabular}

Note: (1) Laminate 1: CSM450 + WR800 + CSM450 + CSM450. (2) Laminate 2: CSM300 + CSM450 + WR800 + CSM450 + Balsa 25mm + CSM450 + WR800 + CSM450 + CSM300.

Table A3 presents the equivalent isotropic properties resulting from the orthotropic laminate of adherents 1 and 2 (see Table A2), using the formulas indicated in Appendix B.1.3. This equivalence is necessary to apply the Bigwood and Crocombe [24] formulas indicated in Section 2.1.2 and Appendix C.

Table A3. Equivalent isotropic properties of adherents.

\begin{tabular}{lccc}
\hline \multicolumn{1}{c}{ Properties } & Symbol & Adherent 1 & Adherent 2 \\
\hline Elasticity modulus $\left(\mathrm{N} / \mathrm{mm}^{2}\right)$ & $E$ & 6171 & 2157 \\
Shear modulus $\left(\mathrm{N} / \mathrm{mm}^{2}\right)$ & $G$ & 2151 & 730 \\
Poisson coefficient & $\mu$ & 0.435 & 0.477 \\
\hline
\end{tabular}

\section{Appendix B}

\section{Appendix B.1. Formulas to Estimate Equivalent Properties}

\section{Appendix B.1.1. Stress-Strain Matrix}

The presented formulas correspond to the stress-strain matrix according to the classical lamination theory. 


$$
\begin{gathered}
{\left[\sigma_{i j}\right]=\left[\begin{array}{cccccc}
\bar{Q}_{11} & \bar{Q}_{12} & \bar{Q}_{13} & 0 & 0 & 0 \\
\bar{Q}_{12} & \bar{Q}_{22} & \bar{Q}_{23} & 0 & 0 & 0 \\
\bar{Q}_{13} & \bar{Q}_{23} & \bar{Q}_{33} & 0 & 0 & 0 \\
0 & 0 & 0 & \bar{Q}_{44} & 0 & 0 \\
0 & 0 & 0 & 0 & \bar{Q}_{55} & 0 \\
0 & 0 & 0 & 0 & 0 & \bar{Q}_{66}
\end{array}\right] \cdot\left[\begin{array}{c}
\varepsilon_{1} \\
\varepsilon_{2} \\
\varepsilon_{3} \\
2 \cdot \varepsilon_{23} \\
2 \cdot \varepsilon_{31} \\
2 \cdot \varepsilon_{12}
\end{array}\right]} \\
A_{i j}=\sum_{k=1}^{N}\left(\bar{Q}_{i j}\right)_{k} \cdot h_{k}, \quad i, j \leq 3 \text { and } i, j=6, \\
A_{i j}=\sum_{k=1}^{N} \frac{h_{k}}{\left(\bar{Q}_{i j}\right)_{k}}, \quad i, j=4,5 .
\end{gathered}
$$

Parameters $\bar{Q}_{i j}$ are defined on Vinson [38].

Properties of orthotropic laminates are defined by Naughton [40]: generalized formulas.

$$
\begin{aligned}
& E_{x}=\frac{A_{11} \cdot A_{22}-A_{12}{ }^{2}}{h \cdot A_{22}}, \quad E_{y}=\frac{A_{11} \cdot A_{22}-A_{12}{ }^{2}}{h \cdot A_{11}}, \quad E_{z}=\frac{A_{11} \cdot A_{33}-A_{13}{ }^{2}}{h \cdot A_{11}} \\
& G_{x y}=\frac{A_{66}}{h}, \quad G_{x z}={\frac{h}{A_{55}}}^{(*)}, \quad G_{y z}={\frac{h}{A_{44}}}^{(*)} \\
& \mu_{x y}=\frac{A_{12}}{A_{22}}, \quad \mu_{x z}=\frac{A_{13}}{A_{33}}, \quad \mu_{y z}=\frac{A_{23}}{A_{33}}
\end{aligned}
$$

$\left.{ }^{*}\right)$ Modified as following [41]

\section{Appendix B.1.2. Formulas to Estimate Properties of Fiber in the Transverse Direction}

The formulas for estimating the modulus of elasticity $z$-direction, shear modulus, and Poisson's coefficient in the $x z$ and yz planes for an individual ply are proposed by Tsai [42]:

$$
\begin{gathered}
E_{z}^{i-p}=2\left[1-\mu_{f}+\left(\mu_{f}-\mu_{m}\right) \cdot V_{m}\right] \cdot\left[(1-C) \frac{K_{f} \cdot\left(2 K_{m}+G_{m}\right)-G_{m} \cdot\left(K_{f}-K_{m}\right) \cdot V_{m}}{\left(2 K_{m}+G_{m}\right)+2\left(K_{f}-K_{m}\right) \cdot V_{m}}+C \frac{K_{f} \cdot\left(2 K_{m}+G_{f}\right)+G_{f} \cdot\left(K_{m}-K_{f}\right) \cdot V_{m}}{\left(2 K_{m}+G_{f}\right)-2\left(K_{m}-K_{f}\right) \cdot V_{m}}\right] \\
G_{x z}{ }^{i-p}=(1-C) \cdot G_{m} \frac{2 G_{f}-\left(G_{f}-G_{m}\right) \cdot V_{m}}{2 G_{m}+\left(G_{f}-G_{m}\right) \cdot V_{m}}+C \cdot G_{f} \frac{\left(G_{f}+G_{m}\right)-\left(G_{f}-G_{m}\right) \cdot V_{m}}{\left(G_{f}+G_{m}\right)+\left(G_{f}-G_{m}\right) \cdot V_{m}}, \\
\mu_{x z} i-p=(1-C) \frac{K_{f} \cdot \mu_{f} \cdot\left(2 K_{m}+G_{m}\right) \cdot V_{f}+K_{m} \cdot \mu_{m} \cdot\left(2 K_{f}+G_{m}\right) \cdot V_{m}}{K_{f} \cdot\left(2 K_{m}+G_{m}\right)-G_{m} \cdot\left(K_{f}-K_{m}\right) \cdot V_{m}}+C \cdot \frac{K_{m} \cdot \mu_{m} \cdot\left(2 K_{f}+G_{f}\right) \cdot V_{m}+K_{f} \cdot \mu_{f} \cdot\left(2 K_{m}+G_{f}\right) \cdot V_{f}}{K_{f} \cdot\left(2 K_{m}+G_{f}\right)+G_{f} \cdot\left(K_{m}-K_{f}\right) \cdot V_{m}},
\end{gathered}
$$

Shear modulus and Poisson's coefficient in the yz plane are equal to those of de xz plane. where:

$$
\begin{aligned}
K_{f} & =\frac{E_{f}}{2\left(1-\mu_{f}\right)}, & K_{m} & =\frac{E_{m}}{2\left(1-\mu_{m}\right)}, \\
G_{f} & =\frac{E_{f}}{2\left(1+\mu_{f}\right)}, & G_{m} & =\frac{E_{m}}{2\left(1+\mu_{m}\right)} .
\end{aligned}
$$

The contiguity factor $C$ is defined by Ueruma [43], as:

$$
C=0.4 V_{f}-0.025
$$

The volume fraction $V_{f}$ of the fiber is determined from [39]:

$$
V_{f}=\frac{f_{c} \cdot \zeta_{R}}{f_{c} \cdot \zeta_{R}-f_{c} \cdot \zeta_{f}+\zeta_{f}} .
$$


Appendix B.1.3. Formulas to Estimate Equivalent Isotropic Properties from Orthotropic Properties

Akasaka [44] proposes formulas to estimate equivalent isotropic properties based on the orthotropic properties defined by Equations (A4)-(A6).

$$
\begin{gathered}
E=\left[\frac{E_{x}+E_{z}+2 \mu_{x z} \cdot E_{z}}{1-\mu_{x z} \cdot \mu_{z x}}\right] \cdot\left[\frac{E_{x}+E_{z}-2 \mu_{x z} \cdot E_{z}+4\left(1-\mu_{x z} \cdot \mu_{z x}\right) \cdot G_{x z}}{3\left(E_{x}+E_{z}\right)+2 \cdot \mu_{x z} \cdot E_{z}+4\left(1-\mu_{x z} \cdot \mu_{z x}\right) \cdot G_{x z}}\right], \\
G=\frac{E_{x}+E_{z}-2 \mu_{x z} \cdot E_{z}}{8\left(1-\mu_{x z} \cdot \mu_{z x}\right)}+\frac{G_{x z}}{2}, \\
\mu=\frac{E}{2 G}-1 .
\end{gathered}
$$

\section{Appendix C}

\section{General Elastic Analysis}

Below the formulas to estimate the distribution of stresses proposed by Bigwood and Crocombe [24] are described:

Normal stress formula:

$$
\sigma_{z}=A_{1} \cdot \cos \left(K_{5} \cdot y\right) \cdot \cosh \left(K_{5} \cdot y\right)+A_{2} \cdot \cos \left(K_{5} \cdot y\right) \cdot \sinh \left(K_{5} \cdot y\right)+A_{3} \cdot \sin \left(K_{5} \cdot y\right) \cdot \cosh \left(K_{5} \cdot y\right)+A_{4} \cdot \sin \left(K_{5} \cdot y\right) \cdot \sinh \left(K_{5} \cdot y\right),
$$

where:

$$
\begin{aligned}
& D_{1}=\frac{E_{1} \cdot h_{1}{ }^{3}}{12 \cdot\left(1-\mu_{1}^{2}\right)}, \quad D_{2}=\frac{E_{2} \cdot h_{2}{ }^{3}}{12 \cdot\left(1-\mu_{2}{ }^{2}\right)}, \\
& K_{5}^{4}=\frac{E_{a}}{4 \cdot t}\left(\frac{1}{D_{1}}+\frac{1}{D_{2}}\right) \\
& A_{1}=\frac{b_{3} \cdot R_{3}-2 \cdot b_{2} \cdot \sinh \left(K_{5} \cdot L\right) \cdot \sin \left(K_{5} \cdot L\right)+b_{1} \cdot R_{6}+b_{4} \cdot R_{1}}{R_{5}}, \\
& A_{2}=\frac{b_{2} \cdot R_{2}-b_{3} \cdot \sinh ^{2}\left(K_{5} \cdot L\right)-b_{1} \cdot R_{4}-b_{4} \cdot \sinh \left(K_{5} \cdot L\right) \cdot \sin \left(K_{5} \cdot L\right)}{R_{5}}, \\
& A_{3}=\frac{b_{2} \cdot R_{2}-b_{3} \cdot \sin ^{2}\left(K_{5} \cdot L\right)-b_{1} \cdot R_{4}-b_{4} \cdot \sinh \left(K_{5} \cdot L\right) \cdot \sin \left(K_{5} \cdot L\right)}{R_{5}}, \\
& A_{4}=b_{1} \\
& b_{1}=\frac{E_{a}}{2 \cdot K_{5}^{2} \cdot t}\left(\frac{M_{c 21}}{D_{2}}-\frac{M_{c 11}}{D_{1}}\right), \quad b_{2}=\frac{E_{a}}{2 \cdot K_{5}^{2} \cdot t}\left(\frac{M_{c 22}}{D_{2}}-\frac{M_{c 12}}{D_{1}}\right), \\
& b_{3}=\frac{E_{a}}{2 \cdot K_{5}{ }^{3} \cdot t}\left(\frac{V_{c 21}}{D_{2}}-\frac{V_{c 11}}{D_{1}}\right), \quad b_{4}=\frac{E_{a}}{2 \cdot K_{5}^{3} \cdot t}\left(\frac{V_{c 22}}{D_{2}}-\frac{V_{c 12}}{D_{1}}\right) \text {, } \\
& R_{1}=\cosh \left(K_{5} \cdot L\right) \cdot \sin \left(K_{5} \cdot L\right)-\sinh \left(K_{5} \cdot L\right) \cdot \cos \left(K_{5} \cdot L\right), \\
& R_{2}=\cosh \left(K_{5} \cdot L\right) \cdot \sin \left(K_{5} \cdot L\right)+\sinh \left(K_{5} \cdot L\right) \cdot \cos \left(K_{5} \cdot L\right), \\
& R_{3}=\cosh \left(K_{5} \cdot L\right) \cdot \sinh \left(K_{5} \cdot L\right)-\cos \left(K_{5} \cdot L\right) \cdot \sin \left(K_{5} \cdot L\right), \\
& R_{4}=\cosh \left(K_{5} \cdot L\right) \cdot \sinh \left(K_{5} \cdot L\right)+\cos \left(K_{5} \cdot L\right) \cdot \sin \left(K_{5} \cdot L\right), \\
& R_{5}=\sinh ^{2}\left(K_{5} \cdot L\right)-\sin ^{2}\left(K_{5} \cdot L\right), \\
& R_{6}=\cosh ^{2}\left(K_{5} \cdot L\right)-\cos ^{2}\left(K_{5} \cdot L\right) .
\end{aligned}
$$


Shear stress formula:

$$
\tau_{y z}=B_{1} \cdot \cosh \left(K_{6} \cdot y\right)+B_{2} \cdot \sinh \left(K_{6} \cdot y\right)+B_{3}
$$

where:

$$
\begin{gathered}
K_{6}{ }^{2}=\frac{4 \cdot G_{a}}{t}\left(\frac{1-\mu_{1}{ }^{2}}{E_{1} \cdot h_{1}}+\frac{1-\mu_{2}{ }^{2}}{E_{2} \cdot h_{2}}\right), \\
B_{1}=\frac{c_{2}-c_{1} \cdot \cosh \left(K_{6} \cdot L\right)}{K_{6} \cdot \operatorname{senh}\left(K_{6} \cdot L\right)}, \quad B_{2}=\frac{c_{1}}{K_{6}}, \quad B_{3}=\frac{c_{3}}{L}-\frac{c_{2}-c_{1}}{K_{6}{ }^{2} \cdot L}, \\
c_{1}=\frac{G_{a}}{t}\left[\frac{1-\mu_{1}^{2}}{E_{1} \cdot h_{1}}\left(T_{c 11}-\frac{6 \cdot M_{c 11}}{h_{1}}\right)-\frac{1-\mu_{2}^{2}}{E_{2} \cdot h_{2}}\left(T_{c 21}+\frac{6 \cdot M_{c 21}}{h_{2}}\right)\right],(* *) \\
c_{2}=\frac{G_{a}}{t}\left[\frac{1-\mu_{1}^{2}}{E_{1} \cdot h_{1}}\left(T_{c 12}-\frac{6 \cdot M_{c 12}}{h_{1}}\right)-\frac{1-\mu_{2}^{2}}{E_{2} \cdot h_{2}}\left(T_{c 22}+\frac{6 \cdot M_{c 22}}{h_{2}}\right)\right],(* *) \\
c_{3}=\left(T_{c 12}-T_{c 11}\right)\left(1-\frac{y}{L}\right)+\left(T_{c 21}-T_{c 22}\right)\left(\frac{y}{L}\right) \cdot(* *)
\end{gathered}
$$

$\left(D_{1}, h_{1}, \mu_{1}, E_{1}\right)$ and $\left(D_{2}, h_{2}, \mu_{2}, E_{2}\right)$ correspond to adherent 1 and adherent 2 , respectively.

$T_{c 11}, V_{c 11}, M_{c 11}, T_{c 12}, V_{c 12}, M_{c 12}$, are the forces applied to the extremes of adherent 1.

$T_{c 22}, V_{c 22}, M_{c 22}, T_{c 21}, V_{c 21}, M_{c 21}$, are the forces applied to the extremes of adherent 2.

$(* *)$ For a better understanding, the nomenclature of the original variables $b_{1}, b_{2}$, and $b_{3}$ of the shear stress formula in [24], are changed to $c_{1}, c_{2}$, and $c_{3}$.

\section{References}

1. Ritter, G.; Speth, D.; Yang, Y. Qualifications of Adhesives for Marine Composite-to-Steel Bonded Applications. J. Ship Prod. 2009, 25, 198-205.

2. Rudiger, J.; McGeorge, D. Science and Technology of Bolt-Adhesive Joints. Adv. Struct. Mater. 2011, 6, 177-199.

3. Hentinen, M.; Hildebrand, M. How to efficiently join FRP structures to metal ships? In Proceedings of the 3rd International Conference on Fast Sea Transportation, FAST'95, Lübeck-Travemünde, Germany, 25-27 September 1995.

4. Hentinen, M.; Hildebrand, M.; Visuri, M. Adhesively Bonded Joints between FRP Sandwich and Metal-Different Concepts and Their Strength Behaviour; Research Notes 1862; VTT Manufacturing Tech., Centre of Finland, VTT Tiedotteita, Meddelanden: Espoo, Finland, 1997; 44p, ISBN 951-38-5183-4.

5. Bohlmann, R.E.; Fogarty, J.H. Demonstration of a composite to steel deck joint on a Navy destroyer. In Proceedings of the 9th International Conference on Marine Applications of Composite Materials, Melbourne, FL, USA, 19-21 March 2002.

6. Kotsidis, E.; Kouloukouras, I.; Tsouvalis, N. Finite element parametric study of a composite to steel join. In Proceedings of the 2nd International Conference on Maritime Technology and Engineering, Lisbon, Portugal, 15-17 October 2014.

7. Shkolnikov, V. Hybrid Ship Hulls, Engineering Design Rationales; Butterworth-Heinemann: New York, NY, USA, 2014.

8. Simler, J.; Brown, L. 21st Century Surface combatants require improved composite to Steel adhesive bonds. AMPTIAC Q. 2003, 7, 21-27.

9. Boyd, S.; Blake, J.; Shenoi, R.; Kapadia, A. Integrity of hybrid steel to composite joints for marine application. Eng. Marit. Environ. 2014, 218, 235-246. [CrossRef]

10. Ozes, C.; Neser, N. Experimental Study on Steel to FRP Bonded Lap Joints in Marine Applications; Dokuz Eylul University, Hindawi Publishing Corporation: Konak, Turkey, 2015.

11. Babazadeh, A.; Reza, M. Finite Element Investigation of Performance of Composite-Steel Double Lap Adhesive Joint Under Tensile Loading. Lat. Am. J. Solids Struct. 2017, 14, 277-291. [CrossRef]

12. Johansson, H. Superstructure in FRP Composites, Saab, 01-41020236-000/Issue 00. 2016. Available online: http://e-lass.eu/media/2016/08/Superstructures-in-FRP-composites-Henrik-Johansson.pdf (accessed on 16 April 2020). 
13. Beeston, A. Developments in fire protection of FRP composite vessels. In Proceedings of the RINA, Innovation in High-Speed Marine Vessels, Freemantle, Australia, 28-29 January 2009; Available online: https://e-lass.eu/media/2016/08/RINA-Conference-Paper.pdf (accessed on 16 April 2020).

14. Dominguez, J.; Carral, L. Hybrid Joint Between Steel Deck and Fiberglass Superstructure. In Proceedings of the Multidisciplinary International Conference of Research Applied to Defense and Security MICRADS, Salinas, Ecuador, 18-20 April 2018; Howlett, R.J., Ed.; Springer: Cham, Switzerland, 2018; Volume 94, pp. 284-295. [CrossRef]

15. Dominguez, J.; Carral, L. Superstructure Design: Combination of Fiberglass Panel and Tubular Structure with Naval Steel Hull. In Proceedings of the 25th Pan-American Conference of Naval Engineering-COPINAVAL, Panama City, Panama, 16-19 October 2017; Sáenz, A.V., Pereira, N.N., Couce, L.M.V., Formoso, J.A.F., Eds.; Springer: Cham, Switzerland, 2018; pp. 81-91. [CrossRef]

16. Volkersen, O. Die Nietkraftverteilung in Zugbeanspruchten Nietverbindungen Mit Konstanten Laschenquerschnitten (The rivet load distribution in lap-joints with members of constant thickness subjected to tension). Luftfahrtforschung 1938, 15, 41-47.

17. Goland, M.; Reissner, E. The stresses in cemented joints. Jpn. Appl. Mech. 1944, 11, A17-A27.

18. Hart-Smith, L. Adhesive Bonded Single Lap Joints; Technical Report NASA CR-112236; National Aeronautics and Space Administration: Hampton, VA, USA, 1973.

19. Hart-Smith, L. Adhesive Bonded Double Lap Joints; Technical Report NASA CR-112235; National Aeronautics and Space Administration: Hampton, VA, USA, 1973.

20. Hart-Smith, L. Non-Classical Adhesive Joints in Practical Aerospace Construction; Technical Report NASA CR-112238; National Aeronautics and Space Administration: Hampton, VA, USA, 1973.

21. Hart-Smith, L. Further Developments in the Design and Analysis of Adhesive-Bonded Structural Joints. In STP749-EB Joining of Composite Materials; Kedward, K., Ed.; ASTM International: West Conshohocken, PA, USA, 1981; pp. 3-31. [CrossRef]

22. Hart-Smith, L. Design Methodology for Bonded-Bolted Composite Joints; Vol I: Analysis Derivations and Illustrative Solutions; Report AFWAL-TR-81-3154; Flight Dynamics Laboratory, AF Wright Aeronautical Laboratories, Wright - Patterson AFB: Montgomery County, OH, USA, 1982.

23. Allman, D. A theory for elastic stresses in adhesive-bonded lap joints. Q. J. Mech. Appl. Math. 1977, 30, 415-436. [CrossRef]

24. Bigwood, D.; Crocombe, A. Elastic Analysis and Engineering Design Formulae for Bonded Joints. Int. J. Adhes. Adhes. 1989, 9, 229-242. [CrossRef]

25. Bigwood, D.; Crocombe, A. Non-Linear Adhesive-Bonded Joint Design Analyses. Int. J. Adhes. Adhes. 1990, 10, 31-41. [CrossRef]

26. Oplinger, D. A Layered Beam Theory for Single-Lap Joints; Report MTL TR 91-23; US Laboratory Command: Adelphi, MA, USA, 1991; p. 44.

27. Zou, G.; Shahin, K.; Taheri, F. An analytical solution for the analysis of symmetric composite adhesively bonded joints. Compos. Struct. 2004, 65, 99-510. [CrossRef]

28. Renton, W.; Vinson, J. The Analysis and Design of Composite Material Bonded Joints Under Static and Fatigue Loadings, Department of Mechanical and Aerospace Engineering, University of Delaware, Air Force Office of Scientific Research. August 1973. Available online: https://apps.dtic.mil/dtic/tr/fulltext/u2/766932.pdf (accessed on 20 April 2020).

29. Ojalvo, I.; Eidinoff, H. Bond Thickness Effects Upon Stresses in Single-lap Adhesive Joints. AIAA J. 1978, 16, 204-211. [CrossRef]

30. Adams, R.; Mallick, V. A method for the stress analysis of lap joints, Taylor \& Francis. J. Adhes. 1992, 38, 199-217. [CrossRef]

31. Smeltzer, S.; Klang, E. Analysis Method for Inelastic, Adhesively Bonded Joints with Anisotropic Adherends, NASA Technical Reports Server, Proceedings of the American Society for Composites 18th Technical Conference, Paper Number 104. January 2003. Available online: https://ntrs.nasa.gov/search.jsp?R= 20040034208 (accessed on 20 April 2020).

32. Echtermeyer, A.; Ekeberg, T.; Sund, O. Long-Term Testing of Composite Through-Thickness Properties; Det Norske Veritas, Research Report 131; Novik: Nordland, Norway, 2004.

33. Hollaway, L. Handbook of Polymer Composites for Engineers; British Plastic Federation: Cambridge, UK, 1994. 
34. Huang, J.; Garnier, C.; Pastor, M.; Gong, X. Rapid evaluation of S-N curve for composite laminates on thermographic approach. MATEC Web Conf. 2018, 165, 1-6. [CrossRef]

35. Nhamoinesu, S.; Overend, M. The Mechanical Performance of Adhesives for a Steel-Glass Composite Façade System. Proceedings of Challenging Glass 3-Conference on Architectural and Structural Applications of Glass, TU Delft, IOS Press BV, Amsterdam, The Netherlands, 28-29 June 2012; Volume 3, pp. 293-306. [CrossRef]

36. Riccio, A.; Sellitto, A. Analytical tool for the preliminary design of an adhesively bonded T joint. Key Eng. Mater. 2015, 665, 285-288. [CrossRef]

37. Hou, J.; Petrinic, N.; Ruiz, C. A Delamination Criterion for Laminated Composites under the Low-Velocity Impact. Compos. Sci. Technol. 2001, 61, 2069-2074. [CrossRef]

38. Vinson, J. Plate and Panel Structures of Isotropic, Composite and Piezoelectric Materials, Including Sandwich Construction; Solid Mechanics and Its Applications; Springer: Dordrecht, The Netherlands, 2005; pp. 1-423. ISBN 1-4020-3111-4.

39. Lloyds Register. Pat 8: Hull Construction in Composite. In Rules and Regulations for the Classification of Special Service Craft; Lloyd's Register Group Limited: London, UK, 2019; pp. 586-722.

40. Naughton, B.; Panhuizen, F.; Vermeulen, A. The elastic properties of chopped strand mat and woven roving in G.R. laminae, Akzo Research, CO. Research Department. J. Reinf. Plast. Compos. 1985, 4, 195-204. [CrossRef]

41. Jones, R. Mechanics of composite materials. In Taylor \& Francis, 2nd ed.; CRC Press: Philadelphia, PA, USA, 1999. [CrossRef]

42. Tsai, S. Structural Behaviour of Composite Materials, National Aeronautics and Space Administration; NASA CR-71: Washington, DC, USA, 1964.

43. Uemura, M.; Yamada, N. Elastic Constants of Carbon Fiber Reinforced Plastic Materials. J. Soc. Mater. Sci. 1975, 24, 156-163. [CrossRef]

44. Akasaka, T. A practical method of evaluating the isotropic elastic constants of glass mat reinforced plastics. Compos. Mater. Struct. Jpn. 1974, 3, 21.

(C) 2020 by the authors. Licensee MDPI, Basel, Switzerland. This article is an open access article distributed under the terms and conditions of the Creative Commons Attribution (CC BY) license (http://creativecommons.org/licenses/by/4.0/). 